\title{
Glycosylation in cancer: mechanisms and clinical implications
}

\section{Salomé S. Pinho ${ }^{1-3}$ and Celso A. Reis ${ }^{1-4}$}

\author{
${ }^{1}$ Instituto de Investigação e Inovação em Saúde (Institute for Research and Innovation in Health), \\ University of Porto, Portugal. \\ ${ }^{2}$ Institute of Molecular Pathology and Immunology of the University of Porto (IPATIMUP), Rua Dr. \\ Roberto Frias s/n, 4200-465 Porto, Portugal. \\ ${ }^{3}$ Institute of Biomedical Sciences Abel Salazar (ICBAS), University of Porto, Rua de Jorge Viterbo \\ Ferreira n.228, 4050-313 Porto, Portugal. \\ ${ }^{4}$ Faculty of Medicine of the University of Porto, Alameda Prof. Hernâni Monteiro
}

Originally published in Nat Rev Cancer. 2015 Sep;15(9):540-55. doi: 10.1038/nrc3982.

\begin{abstract}
Despite recent progress in understanding the cancer genome, there is still a relative delay in understanding the full aspects of the glycome and glycoproteome of cancer. Glycobiology has been instrumental in relevant discoveries in various biological and medical fields, and has contributed to the deciphering of several human diseases. Glycans are involved in fundamental molecular and cell biology processes occurring in cancer, such as cell signalling and communication, tumour cell dissociation and invasion, cell-matrix interactions, tumour angiogenesis, immune modulation and metastasis formation. The roles of glycans in cancer have been highlighted by the fact that alterations in glycosylation regulate the development and progression of cancer, serving as important biomarkers and providing a set of specific targets for therapeutic intervention. This Review discusses the role of glycans in fundamental mechanisms controlling cancer development and progression, and their applications in oncology.
\end{abstract}

\section{INTRODUCTION}

In recent years, glycobiology has gained increased importance in cancer research, given its role in understanding various cancer mechanisms and as it provides a set of targets for diagnostic application and therapeutic strategies1-6. Glycosylation can act as a key regulatory mechanism controlling several physiopathological processes. Defects in glycosylation in humans and their links to disease have shown that the mammalian glycome contains a remarkable amount of biological information7. Glycan diversity arises from differences in monosaccharide composition (for example, 
galactose (Gal) or N-acetylgalactosamine (GalNAc)), in link- age between monosaccharides (for example, between carbons 1 and 3 or carbons 1 and 4), in anomeric state, in branching structures, in other substitutions (such as sulfation state) and in linkage to their aglycone part (protein or lipid)8,9 (FIG. 1). Characterizing the biological functions of each glycan10, as well as those of glycan-binding proteins (including galectins and sialic acid-binding immunoglobulin-type lectins (siglecs)), has been shown to make important contributions to the cancer field1-3,5. Different types of glycoconjugates interfere with key cancer cell processes as well as with the tumour microenvironment, leading to cancer progression. This Review describes how glycans affect and regulate the genesis and progression of cancer. The recent cutting-edge technological developments in glycobiology and their innovative applications in the oncology field are also introduced and discussed.

\section{Glycoconjugates and glycosylation}

Glycosylation is defined as the enzymatic process that produces glycosidic linkages of saccharides to other saccharides, proteins or lipids1,11. Glycoconjugates are primarily defined according to the nature of and linkage to their aglycone (non-glycosyl) part (FIG.1). Glycoproteins carry one or more glycans covalently attached to a polypeptide backbone, usually via nitro- gen or oxygen linkages, in which case they are known as $\mathrm{N}$-glycans or O-glycans, respectively8,12,13 (FIG. 2). A common type of protein $\mathrm{O}$ - glycosylation is ini- tiated via GalNAc - the first monosaccharide that connects serine or threonine in particular forms of protein O-glycosylation (O-GalNAc) called mucin- type O-glycosylation12,13 - which can be extended into various different structures14. There are other types of O-glycans as well, such as those attached via O-mannose, and the nucleocytoplasmic glycan $\mathrm{O}$ - linked $\beta$ - $\mathrm{N}$ - acetylglucosamine (O-GlcNAc) 15 (FIGS 1,2). In addition, other forms of glycosylation exist that occur only in specific types of proteins, such as the Notch receptor, and these have been shown to be impor- tant in cancer cell biology 16 (BOX 1). Moreover, several proteins are linked to the cell membrane through a glycosylphosphatidylinositol (GPI) anchor; these are known as GPI-anchored proteins8 (BOX 2). Other major classes of glycoconjugates include the proteoglycans and glycosphingolipids (FIG.1). Proteoglycans are glycoconjugates that have one or more glycosaminoglycan (GAG), such as chondroitin sulfate, heparan sulfate and keratan sulfate8. Hyaluronan is a GAG primarily found as a free sugar chain. Glycosphingolipids are molecules composed of a glycan linked to a lipid ceramide. The structural and functional classifications of glycosphingolipids have traditionally been based on their glycan part8. The first sugars linked to ceramide in higher animals are typi-cally $\beta$-linked galactose (galactosylceramide) or glucose (glucosylceramide). In vertebrate glycosphingolipids, the glucose moiety is typically substituted with $\beta$-linked galactose, creating a lactosylceramide ( $d$ - galactosyl-1,4- $\beta$ - $d$ - glucosylceramide). Glycosphingolipids include a series of neutral 'core' structures and gangliosides, which typically carry one or several sialic acids and have been shown to regulate receptor tyrosine kinase (RTK) signalling17.

\section{Glycosylation alterations in cancer}

Changes in glycosylation associated with oncogenic transformation were first described over more than six decades ago18,19. Those observations were further corroborated with the advent of monoclonal antibody technology, which showed that tumour-specific antibodies were directed against carbohydrate epitopes and, in most cases, were oncofetal antigens present on tumour 
glycoproteins and glycosphingolipids20,21. Tumour cells display a wide range of glycosyla- tion alterations compared with their non-transformed counterparts. Protein glycosylation increases molecular hetero geneity as well as the functional diversity within cell populations (FIG. 2). This heterogeneity occurs because aberrant glycan modifications are protein- specific, site- specific (different sites on a given protein can be differentially glycosylated) and cell-specific. The specificities of glycosylation depend on various intrinsic factors of the glycosylation process within a given cell or tissue type. Two principal mechanisms underlying the tumour-associated alterations of carbo- hydrate structures were first postulated by Hakomori and Kannagi, in the so-called incomplete synthesis and neo-synthesis processes22. The incomplete syn- thesis process, occurring more often in early stages of cancer, is a consequence of the impairment of the nor- mal synthesis of complex glycans expressed in normal epithelial cells, which leads to the biosynthesis of trun- cated structures, as seen with sialyl Tn (STn) expression in gastrointestinal and breast cancers23,24. Conversely, neo- synthesis, commonly observed in advanced stages of cancer, refers to the cancer-associated induction of certain genes involved in the expression of carbohydrate determinants, as seen in the de novo expression of cer- tain antigens (such as sialyl Lewis a (SLea) and SLex) in many cancers25. In general, a shift from the normal glycosylation pathway occurs in cancer cells, leading to altered glycans expression owing to one or various factors. First, altered expression of glycans can be attributed to under- or overexpression of glycosyltransferases (owing to dys- regulation at the transcriptional level25-28, dysregulation of chaperone function29,30 and/or altered glycosidase activity31). Second, altered glycan expression can be due to changes in the tertiary conformation of the peptide backbone and that of the nascent glycan chain. Third, the differences can stem from the variability of vari- ous acceptor substrates as well as the availability and abundance of the sugar nucleotide donors and cofac- tors32. Finally, changes in glycan expression can be due to the expression and localization of the relevant glycosyltransferases in the Golgi apparatus33,34. Mislocalization and/or changes in the activity of the glycosyltransferases results in the synthesis of imma- ture core glycan structures35,36. Studies have shown that early acting enzymes synthesizing core $O^{-}$glycans, such as GalNAc transferases, core 1 GalNAc $\beta_{1}$, $3^{-}$ga lactosyltransferase 1 ( $\mathrm{C}_{1} \mathrm{GalT}_{1}$ ) and core $2 \beta_{1}, 6-\mathrm{N}^{-}$acetylglucosaminyltransferase $\left(\mathrm{C}_{2} \mathrm{GnT}\right)$, are enriched in cis- and medial-Golgi cisternae34,37, whereas late- acting enzymes (such as sialyltransferases) are enriched in trans-Golgi cisternae. In cells, overexpression of $\alpha$-GalNAc $\alpha$ - 2,6- sialyltransferase I (ST6GalNAc- I; encoded by ST6GALNAC1), the enzyme responsible for STn biosynthesis23,24,38, leads to expression of enzymes in all Golgi cisternae and disrupts glycosylation by pre- maturely adding sialic acid to form the STn antigen 36,38 . The most- widely occurring cancer-associated changes in glycosylation are sialylation, fucosylation, $\mathrm{O}$-glycan truncation, and $\mathrm{N}$ - and O- linked glycan branching2,39,40 (FIGS 2,3).

Sialylation. Sialylation is an important modification in cellular glycosylation, as sialylated carbohydrates have an important role in cellular recognition, cell adhesion and cell signalling. An increase in global sialylation - especially in $\alpha 2,6^{-}$and $\alpha 2,3^{-}$linked sialylation - owing to altered glycosyltransferases expression has been closely associated with cancer41. The lactosaminic chains are frequently terminated with a sialic acid. For example, $\alpha 2,6$ - sialylated lactosa- mine (Sia6LacNAC) is the product of $\beta$-galactoside $\alpha 2,6$ - sialyltransferase I (ST6Gal-I) 42 , an enzyme with altered expression in various malignancies - includ- ing colon, stomach and ovarian cancer 42 - and that has been reported to be a predictive marker of poor progno- sis in colon cancer43. Other major sialylated antigens associated with cancer are SLea and SLex (REF. 2) (FIG. 2). SLea and SLex have been demonstrated to be highly expressed in many malignant cancers, and SLex expression levels have been correlated with poor survival in cancer patients44,45. SLex is the 
well-known ligand for selectins46, which are vascular cell adhesion molecules that belong to a family of C-type lectins (which require calcium for binding). During inflammation, selectins mediate the initial attach - ment of leukocytes to the endothelium during the process of leukocyte extravasation46. In cancer, SLex interactions with selectins regulate the metastatic cascade by forming emboli of cancer cells and platelets and favouring their arrest on endothelia (FIG. 4), therefore determining the malignant behaviour and development of metastasis47. Tumour metastasis has been shown to be attenuated in animal models by the use of specific GAGs, such as heparin, that inhibit $\mathrm{P}$-selectin-mediated interactions of platelets with carcinoma cell-surface ligands48. The SLea tetrasaccharide, which is detected by the serological assay CA19-9, is a cancer- associated marker widely used in the clinical practice. The CA19- 9 assay has been mostly applied in patients with an established diagnosis of pancreatic, colorectal, gastric or biliary can- cer and used to monitor clinical response to therapy3,49. In addition, elevated preoperative concentrations of CA19- 9 have been shown to be associated with poor prognosis in colon and gastric carcinoma5o. Increased sialylation in cancer also includes the expression of polysialic acid, which is associated with several types of cancers and is frequently expressed in high-grade tumours 51,52. Polysialic acid can often be pre- sent in neural cell adhesion molecule 1 (NCAM1), and this is associated with aggressiveness and poor clinical outcome in cancers, including lung cancer, neuroblastoma and gliomas51,52. Gangliosides are also overexpressed in tumours such as melanoma, neuroblastoma and breast cancer, in which they mediate cell proliferation, tumour growth and cancer cell migration 17,53 .

\section{Box 1 | The unique type of Notch glycosylation}

Notch signalling is essential for cell fate, and dysregulation of the pathway leads to various human diseases, including cancerg6. Glycosylation of the Notch extracellular domain has been shown to regulate Notch activityg6. The Notch ligands (the Delta, Serrate and LAG-2 family of proteins) bind to the extracellular domain of Notch receptor, triggering its activation by inducing a conformational change that exposes cleavage sites in Notch. Cleavage at these sites results in liberation of the Notch intracellular domain, which translocates to the nucleus and controls the transcriptional activation of the transcription factor recombining binding protein suppressor of hairless (RBP-JK). The Notch extracellular domain is modified with different types of carbohydrates, including Asplinked $\mathrm{N}$-glycans and several $\mathrm{O}$-glycans, such as $\mathrm{O}$-fucose208. $\mathrm{O}$-fucose monosaccharides are elongated to a $N$-acetylglucosamine $\beta_{1-3}$ fucose (GlcNAc $\beta_{1-3}$ Fuc) disaccharide by the action of the Fringe $\mathrm{N}$-acetylglucosaminyltransferase in Drosophila melanogaster and by the Fringe homologues in vertebrates96,209. The disaccharide can be further elongated to the tetrasaccharide Neu5Aco2-3/6Gal $\beta_{1-4}$ GlcNAc $\beta_{1-3}$ Fuc by the sequential action of several glycosyltransferases in mammalsg6.

Fringe was demonstrated to be a modulator of Notch activity209. Three Fringe homologues exist in mammals: lunatic fringe, manic fringe and radical fringe210. Notch regulation by glycosylation, such as the addition of GIcNAc by Fringe, was shown to interfere with Notch-ligand interactions, promoting Notch-Delta binding and reducing Notch-Serrate binding96, 209.

Several studies have reviewed the mechanisms of glycosylation in the regulation of this important receptor in cancerg6. Glycosylation-dependent modulation of Notch signalling controls development, maintains tumour cell 'stemness' and mediates cancer metastasisg6. 
Fucosylation. Fucosylation has been also associated with cancer. Fucosylated glycans are synthesized by a range of fucosyltransferases (Fuc- Ts; Fuc- TI-Fuc- TXI (encoded by FUT1-FUT11, where FUT3 is also known as the Lewis gene, Le)), with fucosylation existing as a non- extendable modification and being generally sub- divided into terminal fucosylation (giving rise to spe- cific Lewis blood-group antigens, such as Lex and Ley and Lea and Leb) and core fucosylation54. The ter- minal steps of the biosynthesis of SLe antigens include the $\alpha 1,3^{-}$or $\alpha 1,4^{-}$fucosylation of a previously $\alpha 2,3^{-}$sialylated type 1 (SLea) or type 2 (SLex) chains54,55 (FIG. 2). The enhanced expression of SLex in adult T cell leukaemia cells has been shown to be dependent on Fuc- TVII activity. The aetiologic agent of this leukaemia, the human T-lymphotropic virus 1 (HTLV-1) retrovirus, encodes a transcriptional activator protein, TAX, which regulates the FUT7 gene encoding Fuc- TVII, the limiting enzyme controlling SLex synthesis in leukocytes56. In breast tumours, the expression of SLex seems to be regulated mainly by Fuc- TVI (encoded by FUT6) 57 . However, the biosynthesis of SLe antigens in gastro- intestinal cancer may depend on the coordinated expres- sion of several glycosyltransferases. The expression of both SLex and SLea antigens expressed by glycolipids in colon cancer tissues has been related to the activation of a

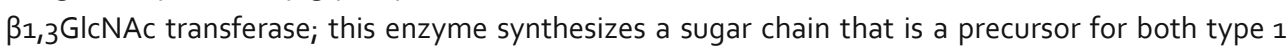
and 2 Lewis structures58. A similar mechanism was observed in gastritis induced by Helicobacter pylori59,60, a bacterium that expresses adhesins that recognize glycan receptors expressed by the gastric epithelium subsequently causing gastric ulcers and, potentially, gastric carcino genesis 5 (BOX 3). Fuc- TVI has also been reported as a major enzyme modulating the SLex biosynthesis in colorectal cancer (CRC)61. Core fucosylation consists in the addition of $\alpha 1,6$-fucose to the innermost GICNAc residue of $\mathrm{N}$-glycans through the action of Fuc-TVIII (encoded by FUT8) (FIG. 2). Overexpression of FUT8 and core fucosylation is an important feature in several cancers, such as lung cancer and breast cancer62,63. This increased core fucosylation is reflected in the serum levels during the process of hepatocarcinogenesis64. Interestingly, core fucosylation of $\alpha$-fetoprotein is an approved biomarker for the early detection of hepa- tocellular carcinoma (HCC), distinguishing it from chronic hepatitis and liver cirrhosis65. In breast cancer, increased core fucosylation of epidermal growth factor receptor (EGFR) was associated with increased dimerization and phosphorylation, which resulted in increased EGFR-mediated signalling associated with tumour cell growth and malignancy 62,66 .

Branching and bisecting GlcNAc N-glycans. During malignant transformation, a frequently occurring glycosylation change in cancer cells is the increased expression of complex $\beta_{1,6}$-branched $\mathrm{N}$-linked glycans2,67 (FIGS 2,3). Increased GlcNAc-branching $\mathrm{N}$-glycan expression is due to increased activity of $\mathrm{GnT}-\mathrm{V}$, which is encoded by the mannoside acetylglucosaminyltransferase 5 (MGAT5) gene. MGAT5 expression is regulated by the RAS-RAF-MAPK sig- nalling pathway, which is activated in cancer67. Branched $\mathrm{N}$ - glycans are further modified by $\beta_{1,4}$-GalTs and elongated with poly- $N$-acetyllactosamine (repeats of Gal $\beta_{1,4}$ GlcNAc $\beta_{1}, 3$ ) by $\beta 1,3^{-G n T s}$, and further capped with sialic acid and fucose. This poly- $\mathrm{N}$-acetyllactosamine structure is a ligand for galectins, a family of con- served carbohydrate-binding proteins, which form galectin-glycan structures termed 'lattices' (REF. 68). Galectins have important roles in cancer, contribut - ing to neoplastic transformation, tumour cell survival, angiogenesis and tumour metastasis69. Overexpression of MGAT5 in an immortalized lung epithelial cell line resulted in loss of contact inhibition, increased cell motility and tumour formation in athymic mice70, as well as in enhanced invasion and metastasis in mouse mammary carcinoma cells71. Moreover, early events in breast carcinoma formation in a Her2- transgenic mouse mammary tumour model were found to be regulated by $\mathrm{GnT}^{-} \mathrm{V}_{72}$. In addition, downregulation of $\mathrm{GnT}-\mathrm{V}$ in mouse mammary cancer cell 
lines resulted in a significant suppression of tumour growth and metastasis71. Breast cancer progression and metastasis induced by a viral oncogene in transgenic mice is markedly suppressed in Mgat5-deficient background73. Moreover, GnT-V- mediated glycosylation regulates the colon cancer stem cell compartment and tumour progression through WNT signalling74. In contrast to the function of GnT-V, GnT- III (encoded by MGAT3) catalyses the addition of bisect- ing GIcNAc $N$-glycans in a $\beta_{1,4}$ - linkage, suppressing additional processing and elongation of $\mathrm{N}$ glycans such as the $\beta_{1}, 6$ - branching structures. GnT- III coun- teracts the role of GnT- V in cancer, being involved in the suppression of cancer metastasis75. MGAT3 trans- fection into mouse melanoma $\mathrm{B} 16$ cells with high metas tatic potential resulted in a significant reduction of $\beta_{1}, 6 \mathrm{Gl}$ cNAc branching (owing to GnT-III and GnT-V enzymatic competition), leading to a significant sup- pression of lung metastasis in mice. GnT- III suppresses tumour metastasis through the regulation of key glyco- proteins, such as EGFR, integrins and cadherins66,76, as described below.

Truncated O-glycans. Another common feature of tumours is the overexpression of truncated O-glycans (FIGS 2,3). The GaINAc-type O-glycans, also called mucin- type O-glycans, are frequently found in most transmem- brane and secreted glycoproteins. During malignancy, aberrant glycosylation also occurs in glycoproteins that display abnormal expression of shortened or truncated glycans, such as the disaccharide Thomsen-Friedenreich antigen ( $T$ antigen, also known as core 1) and the mono- saccharide GalNAc (also known as Tn) and their sia- lylated forms (ST and STn (Neu5Aco2-6GalNAco-O-R), respectively), which result from the incomplete synthesis of O-glycans77. Altered expression of polypeptide GalNAc trans- ferases (ppGalNAcTs) - the enzymes initiating the mucin- type O- glycosylation12,13 - is often observed in cancer78,79. The ppGalNAcTs control the sites and density of O-glycan occupancy 12,13, and changes in their expression lead to alterations in $\mathrm{O}$ - glycosylation8o. In addition, enzymes competing for the same substrate can also induce expression of truncated glycans and exposure of protein epitopes that would other- wise be hidden in the normally glycosylated protein. The relative enzymatic activities of $\mathrm{C}_{2} \mathrm{GnT}$ and $\alpha 23^{-}$sialyltransferase I ( $\mathrm{ST}_{3} \mathrm{Gal}-\mathrm{I}$ ) have been shown to determine the $\mathrm{O}^{-}$glycan structure in cancer cells81. These relative activities underlie the aberrant expres- sion of a tumour- associated epitopes on glycoproteins, such as mucins in breast 81 and gastric 82 cancers. STn is rarely expressed in normal healthy tissues but can be detected in most carcinomas, such as those from the pancreas83,84, stomach23,85,86, colorectum23,87, breast38, bladder88 and ovary89, correlating with decreased cancer cell adhesion, increased tumour growth, increased tumour cell migration, invasion and poor prognosis. The abnormal synthesis of STn in cancer occurs owing to the overexpression of ST6GalNAc-I. Mutations in T-synthase $\mathrm{C}_{1} \mathrm{GalT}_{1}$ - specific chaperone 1 ( $\left.\mathrm{C}_{1} \mathrm{GALT}_{1} \mathrm{C}_{1}\right)$ - which blocks further $\mathrm{O}^{-}$glycan elongation and shifts the pathway towards generation of $\mathrm{Tn}-$ can also lead to STn expres sion through the action of ST6GaINAc- 190,91 (FIG. 2).

Therefore, STn has been proposed as an important prognostic marker and a target for the design of anticancer vaccines92,93. 


\section{Box 2 | GPI-anchored proteins and disease}

Glycosylphosphatidylinositol (GPI)-anchored proteins are formed by a glycan bridge between phosphatidylinositol and a phosphoethanolamine, which is then linked to the carboxy-terminal amino acid of a protein. This structure typically constitutes the only anchor to the lipid bilayer membrane for some proteins8. Mutation in the GPI phosphatidylinositol $\mathrm{N}$-acetylglucosaminyltransferase subunit A (PIGA) gene leads to defects in the synthesis of the GPI anchor, resulting in deficiency of all GPI-bound proteins. Haematopoietic stem cells that are defective in GPI anchor assembly owing to a mutation in the PIGA gene preferentially expand in the bone marrow and give rise to defective peripheral blood elements that are deficient in GPIanchored protein expression. Mutation in the X-linked PIGA gene causes paroxysmal nocturnal haemoglobinuria, a disease characterized by haemolytic anaemia, thrombosis and impaired bone marrow function, with an increased risk of developing leukaemia211.

\section{Glycosylation in the cancer cell}

Glycans have been found to participate in numerous fun- damental biological processes involved in cancer, such as inflammation (BOX 3), immune surveillance, cell-cell adhesion76,94,95, cell-matrix interaction76, inter- and intracellular signalling96-99, and cellular metabolism100,101 (FIG. 4). Furthermore, glycans alter protein conformation and structure, thereby modulating the functional activity of the protein102. Unravelling the biological significance of glycan-based interactions in cancer can contribute to the deciphering of molecular mechanisms underlying the biology of cancer.

Glycosylation in tumour cell-cell adhesion. The devel- opment of malignant tumours is in part characterized by the ability of a tumour cell to overcome cell-cell adhesion and to invade surrounding tissue. Epithelial cadherin (E-cadherin) is a transmembrane glycopro- tein103 and a major epithelial cell-cell adhesion mole- cule in cancer104. Glycans can have a profound effect on tumour cell-cell adhesion by directly interfering with $\mathrm{E}$ - cadherin functions. GnT-V overexpression in gastric cancer cells induces $\mathrm{E}$ - cadherin cellular mislocalization from the cell membrane into the cytoplasm and its functional impairment94,95. The addition of GnT-V-mediated $\beta_{1}, 6$ GlcNAc-branched $\mathrm{N}$-glycans to $\mathrm{E}$-cadherin leads to incorrectly assembled and non-functional adherens junctions, which compromise cell-cell adhesion94,95,105 and downstream signalling pathways106, contributing to tumour invasiveness and metastases107. Preventing this aberrant glycosylation in a specific Asp site improves $E$-cadherin functions in cancer108. Interestingly, patients with gastric carcinoma displaying loss of E- cadherin function (not explained at the genetic or structural level) exhibit an increase in $\beta_{1}, 6 \mathrm{GlcNAc}$ - branched $\mathrm{N}$ - glycans on E-cadherin5,94. Conversely, GnT- III- mediated bisecting GlcNAc N- glycans counteract GnT- V activity through $\mathrm{E}$-cadherin regulation75,94. This $\mathrm{E}$ - cadherin glycan modification was associated with a delayed turnover rate at cell membrane94,109, inhibition of endocytosis94, decreased phosphorylation of $\beta$-catenin that remained in complex with $E$-cadherin110, and increased stability of adherens junctions, promoting tumour suppression5,94,95. Moreover, expression of GnT-III is also associated with suppression of epithelial-to-mesenchymal transition 28,111 . Therefore, a mutual regulatory mechanism between $\mathrm{E}$-cadherin-mediated cell-cell adhesion and its glycosylation exists in cancer, which is controlled by the competitive action of GnT- III and 
$\mathrm{GnT}-\mathrm{V}$, and can culminate in either tumour suppression or tumour metastasis, respectively5,112 (FIG. 4). Cancer cells produce increased levels of sialylated glycans, leading to the high expression of tumour- associated antigens2,113. Increased expression of sialylated antigens promotes cell detachment from the tumour mass through electrostatic repulsion of nega- tive charges, which physically inhibits and disrupts cell-cell adhesion114,115. Transfection of breast cancer cells with ST6Gal-I results in increased cell migra- tion and decreased cell-cell adhesion in vitro116 (FIG. 4). Furthermore, sialylated glycans (such as SLex) can pro- mote the adhesion of tumour cells to vascular endothe- lial cells through their interaction with selectins, such as $\mathrm{E}^{-}$- selectin, mediating the initial steps of the forma- tion of cancer metastases2 (FIG. 4). In addition, de novo expression of STn in gastric carcinoma cells modulates the malignant phenotype, inducing more- aggressive cell behaviour, with decreased cell-cell aggregation and increased matrix interaction, migration and invasion85. RNA interference- mediated gene silencing of ST6GALNAC 1 suppresses the metastatic potential of gastric cancer cells owing to a reduction in expression of insulin growth factor I (IGF- I) and reduced activa- tion of signal transducer and activator of transcription, STAT 5 B 117. Furthermore, somatic mutations and hyper- methylation of $\mathrm{C}_{1} \mathrm{GALT}_{1} \mathrm{C}_{1}$ have shown that loss of $\mathrm{C}_{1} \mathrm{GALT}_{1} \mathrm{C}_{1}$ function leads to STn expression, preventing cell-cell interactions and contact inhibition of cell growth in cancer cells84. Clinically, increased sialylation is often associated with invasiveness and poor prognosis of cancer patients 44,47 .

Glycosylation in cell-matrix interaction and signalling. The extracellular matrix (ECM) is composed of a dynamic and complex array of glycoproteins, collagens, GAGs and proteoglycans. It provides mechanical and structural sup- port, as well as spatial context, for signalling events, with direct implications in tumour development, maintenance of stem cell niches and cancer progression118. Heparan sulfate proteoglycans (HSPGs) are present on the cell surface and in the ECM and can modulate cell growth and differentiation, controlling embryogenesis, angiogenesis and homeostasis. HSPGs contain one or more covalently attached heparan sulfate GAG chains119. There are different groups of HSPGs classified according to their location: membrane HSPGs, such as syndecans and the GPI- anchored proteoglycans, the glypicans; the ECM HSPGs, such as agrin, perlecan and type XVIII collagen; and the secretory- vesicle HSPG, serglycin119. HSPGs can bind cytokines, chemokines and growth factors, protecting them against proteolysis; in addition, HSPGs can act as co-receptors for various growth factors for tyrosine kinase receptors, lowering their activation thresholds or changing the duration of their signalling reactions119 (FIG. 4). Overexpression of proteoglycans occurs in several cancers in which the heparan sulfate chains covalently bound to the proteoglycans can modulate the activation of protein receptors, such as HER2, EGFR, MET (also known as hepatocyte growth factor receptor (HGFR)) and transforming growth factor $\beta$ (TGF $\beta$ )120. Heparan sulfate chains regulate the interactions121, and increase the solubility, of various signalling molecules122, therefore increasing their access to receptors and facilitating signal transduction. For instance, heparan sulfate chains can release HGF, inducing cell growth and motility through interaction with MET121, which is frequently activated in cancer cells99 (FIG.4). Heparan sulfate chains can also release vascular endothelial growth factor A (VEGFA), a regulator of angiogenesis that stimulates growth, motility, and tubulogenesis in vascular endothelial cells through interactions with VEGF receptor 1 (VEGFR1) and VEGFR2 (REF. 121). Another important membrane receptor involved in matrix-dependent cell motility and migration is $\mathrm{CD}_{44}$, which is the main receptor for hyaluronic acid. $\mathrm{CD}_{44}$ is a multifunctional cell surface molecule involved in can- cer cell proliferation, differentiation, migration and signalling123. CD44 splicing variants have been associated with tumour development and progression124. The role of CD44 glycosylation in matrix- dependent cell adhe- sion, motility and 
migration is far from being elucidated. Nevertheless, evidence has shown that changes in glycosylation of $\mathrm{CD}_{44}$ can markedly influence hyaluronic acid ligand recognition and binding, modifying cancer cell signalling125. Treatments of $\mathrm{CD}_{44}$ with inhibitors of glycosylation and de- glycosylating enzymes signifi- cantly change the binding to hyaluronic acid, modulating CD44-dependent signalling and function126. Moreover, glycosylation modification of $\mathrm{CD}_{44}$ induced by transfection of $\alpha 1,2-F u c^{-} T$ enhanced cell motility and tumori- genicity in rat carcinoma cells127. Additionally, GAG forms of $\mathrm{CD}_{44}$ containing chondroitin and heparin sul- fate chains modulate the binding of tumour cells to fibro- nectin128. Proteoglycans are also involved in the biogenesis and recognition of exosomes, which are secreted vesicles of endosomal origin involved in signalling processes129. Syndecans control the interaction with key acces- sory components of the endosomal- sorting complexes required for transport machinery. In addition, hepara- nase modulates syndecan-controlled pathways, foster- ing endosomal membrane budding and the biogenesis of exosomes by trimming the heparan sulfate chains on syndecans and controlling the selection of specific cargo to exosomes129. Hyaluronidases also have many roles in cancer metastasis by participating in the degradation of the ECM surrounding the tumour, enabling cancer cells to disseminate from the primary tumour and allowing invasion by degradation of the basement membrane and by clearing the ECM of the secondary site1zo. Recent studies demonstrated that expression of bulky glycoproteins in the cancer cell glycocalyx facilitates integrin clustering by funnelling active integrins into adhesions and by applying tension to matrix-bound integrins, independently of actomyosin contractility131. Expression of large tumour- associated glycoproteins in non-transformed cells facilitates integrin-dependent growth factor signalling to support cell survival, further confirming that alterations of glycoprotein expres- sion in the cancer cell glycocalyx could foster invasion and metastasis by mechanically enhancing cell-surface receptor function131. Cell-ECM interactions play essential parts during the acquisition of migration and invasive behaviour of tumour cells132. Integrins are carriers of $\mathrm{N}$-glycans and are important receptors for signals in the ECM and connect many biological functions, such as cell proliferation, protection against apoptosis and malignant transformation131. Integrin expression is upregulated in migratory cells associated with tumour metastases 133 . $\mathrm{N}$ - glycans on $\alpha_{5} \beta_{1}$ integrin, a receptor for fibronectin (encoded by $\mathrm{FN} 1$ ), are required for $\alpha \beta$-heterodimer formation and for proper integrin-matrix inter action76. Changes in $\mathrm{N}$-glycans in cancer can regulate integrins functions. Transformation of $\mathrm{NIH}_{3} \mathrm{~T}_{3}$ cells with an oncogenic RAS gene resulted in enhancement of cell spreading on fibronectin due to increased modifica- tion of $\alpha_{5} \beta_{1}$ integrins with

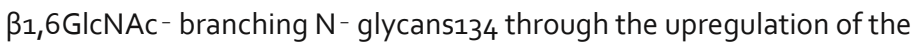

RAS-RAF-MAPK signalling pathway and subsequent activation of MGAT5 transcription. Similarly, over- expression of human fibrosarcoma cells with $\mathrm{GnT}$ - $\mathrm{V}$ resulted in an increased cell migration towards fibro- nectin and invasion through the Matrigel due to an increase in $\beta_{1}, 6$-branching $\mathrm{N}$-glycans on $\alpha_{5} \beta_{1}$ integrin135. Moreover, the characterization of carbohydrate moieties of $\alpha_{3} \beta_{1}$ integrin, the receptor for laminin- 5 showed that $\beta_{1}, 6 \mathrm{GlcNAc}$-branched structures were highly expressed in metastatic human melanoma cells136. Changes in $N$-linked $\beta 1,6$-branching occurring dur- ing oncogenesis alter cell-matrix adhesion and migration by inhibiting the clustering of integrins and subsequent signal transduction pathways136. In contrast to the over- expression of $\mathrm{GnT}-\mathrm{V}$, the overexpression of GnT-III resulted in an inhibition of $\alpha_{5} \beta_{1}$ integrin-mediated cell spreading and migration, and the phosphorylation of focal adhesion kinase (FAK). The affinity of the binding of $\alpha_{5} \beta_{1}$ integrin to fibronectin was greatly reduced as a result of the introduction of a bisecting GlcNAc N-glycans on the $\alpha_{5}$ subunit137. Similarly, in MKN45 gas- tric cancer cells, the overexpression of GnT-III suppresses $\alpha_{3} \beta_{1}$ integrin-mediated cell migration on laminin-5, 
counteracting the GnT-V activity138. Overall, GnT- III is described to suppress cancer metastases by at least two major mechanisms: an enhancement in cell-cell adhesion and a downregulation of cell-ECM adhesion139. Furthermore, an increased terminal $\alpha 2,6$ - sialylation of integrins $\mathrm{N}$ - glycans can control cancer cell migratory and metastatic potential, interfering with the ligand- binding properties of integrins101,140. Analysis of cancer cells that overexpress ST6Gal1 consistently indicates altered adhesion of cells to ECM substrates, such as colla gen, fibronectin and laminin in colon cancer141 and breast cancer cell lines116. Additionally, altered $\mathrm{N}$ - glycosylation of integrins can have an impact on their cis-interaction with membrane- associated receptors, including EGFR142 and the tetra- spanin family of proteins, as well as gangliosides in the microdomain. Glycosylation of $\alpha_{3} \beta_{1}$ integrin was dem- onstrated to regulate its association with the tetra spanin $\mathrm{CD}_{151}$, modulating cell spreading and motility143. Therefore, changes in the $\mathrm{N}$-glycosylation profile of integ- rins modulate tumour cell motility and migration through interference with the supramolecular complex formation (tumour cell focal adhesions) on the cell surface. In the formation of these focal adhesions, integrins interact with HSPG on the surface of tumour cells144. Syndecan- 4 is frequently upregulated in a range of cancers 145 ; it binds to fibronectin and laminin- 5 enhancing the function of $\beta_{1}$ integrin during cell spreading146. Similarly, syndecan- 1 was described to functionally couple with $\alpha v \beta_{3}$ integrin in breast cancer cells, resulting in increased $\alpha \vee \beta_{3}$ - dependent cell spreading and migration147.

\section{Box 3 | Glycosylation at the interface of inflammation-induced cancer}

During inflammation, a considerable number of glycosylation changes occur, and some of these have been associated with the carcinogenesis process. Helicobacter pylori, a Gram-negative bacterium specialized in the colonization of the human stomach, can cause gastric ulcers, and persistent infection may cause chronic atrophic gastritis with the development of intestinal metaplasia, dysplasia and gastric carcinoma5. The adhesion of $H$. pylori to the gastric mucosa is mediated by different bacterial adhesins that recognize glycans expressed by the gastric mucosa. The antigen-binding adhesin BabA binds to fucosylated antigens normally expressed by secretor individuals212, and the sialic acid-binding adhesin SabA recognizes sialylated Lewis glycans (sialyl Lewis a (SLea) and SLex) expressed in gastritis213. Inflammation-induced glycosylation alterations, such as the aberrant overexpression of SLex, occur because of changes in glycosyltransferases expression59,60,214. Changes in glycosylation have also been studied in acute-phase proteins, such as $\alpha_{1}$ antitrypsin, as potential biomarkers in cancer and in acute and chronic inflammatory conditions215. Furthermore, glycosylation alterations have been shown to correlate with disease severity in certain inflammatory conditions, such as in inflammatory bowel disease216. In addition, glycosylation alterations have been reported in circulating proteins produced by the liver in patients with inflammatory diseases, such as gastritis203 and pancreatitis215.

Several studies have shown that the sialic acid $\mathrm{N}$-glycolylneuraminic acid (Neu5 $\mathrm{Gc}$ ) is enriched in red meat, an epidemiological risk factor for cancer development217. Humans cannot synthesize Neu ${ }_{5} \mathrm{Gc}$ because the human gene cytidine monophosphate- $N$-acetylneuraminic acid hydroxylase $(C M A H)$, which encodes the enzyme responsible for the synthesis of CMP-Neu5Gc from CMP-N-acetylneuraminic (CMP-Neu5Ac) acid is irreversibly mutated. The active form of CMAH is found in apes218, and the mutated CMAH form is estimated to have originated 2-3 million years ago, prior to the emergence of the genus Homo218. Neu5Gc has been shown to be bioavailable, undergoing metabolic incorporation into human tissues. Human-like Neu5Gc-deficient mice have been shown to develop inflammatory conditions when fed with Neu5Gc and challenged with 
Neu5Gc-specific antibodies. Such mice developed hepatocellular carcinomas217. These studies demonstrate the potential role in cancer development of the sialic acid Neu5Gc and provide an explanation for the epidemiological association between red meat consumption, inflammation and cancer risk.

Glycosylation in cancer metabolism and signalling. A key feature of cancer cell metabolism is a shift from oxidative phosphorylation to aerobic glycolysis (the Warburg effect) 148 , which is characterized by high rates of glucose uptake to cope with the increased energetic and biosynthetic needs to generate a tumour. Additionally, to help meet increased biosynthetic demands, cancer cells also upregulate glutamine uptake. The abundance of glucose in the cytoplasm of cancer cells not only contributes to increased glycolysis but also increases flux into the metabolic branch pathways, such as the hexo samine biosynthetic pathway (HBP). Approximately $3-5 \%$ of the total glucose entering a cell is shunted through this pathway149. Therefore, increased glucose and glutamine uptake by cancer cells probably drives increased HBP flux. The end-product of HBP is uridine diphosphate (UDP) - GIcNAc, which is a critical metabolite that is subsequently used for OGlcNAcylation as well as for O- and N-glycosylation150. Given O-GlcNAcylation responsiveness to the glucose flux, O-GIcNAc can act as a 'nutritional sensor' (REF. 151). Increased levels of O- GIcNAc transferase (OGT) have been found in breast cancer, and knockdown of OGT in vitro reduces cancer hyper-O-GlcNAcylation and inhibits tumour growth, invasion and metastasis, further indicating that elevated O-GIcNAc contributes to cancer progression152-154. Moreover, O- GIcNAc modulates key protein functions by regulating protein phosphorylation, altering protein degradation, controlling protein localization and mediating transcription155. O-GlcNAc modifications have been implicated in key molecular events occurring in cancer, such as tumour cell proliferation (by regulating the activities of transcription factor forkhead box protein $\mathrm{M}_{1}$ (FoxMl) and cyclin $D_{1}$, which are both involved in cell cycle progression154), cancer cell survival and angiogenesis (through the effect of hyper-O-Glc- NAcylation (via activation of nuclear factor KB-mediated signalling153) and upregulation of VEGFA and matrix metalloproteinases (MMPs)156, respectively), and cancer cell invasion and metastasis (through O-GlcNAc regulation of $\mathrm{E}$ - cadherin trafficking and function)157. Many oncogene and tumour-suppressor gene products were shown to be modified by O-GlcNAc158. MYC undergoes O- GlcNAcylation at Thr58, which is also a phosphorylation site. In fact, O- GlcNAcylation has extensive crosstalk with phosphorylation and serves as a nutrient sensor to modulate signalling, transcription and cytoskeletal functions158. Altered phosphorylation events affect GlcNAcylation levels and vice versa. Increased MYC O- GlcNAcylation competes with phos- phorylation, stabilizing MYC and thus contributing to oncogenesis159. This type of interplay also occurs with the p53 tumour-suppressor protein16o. Similarly to O-GlcNAcylation, $\mathrm{N}$-glycan branching is nutrient sensitive, with functional consequences for the cancer cell. The degree of $\mathrm{N}$ - glycan branching modulates the activity and/or signalling and surface retention of many cell surface proteins, including growth factor receptors97. Cell surface glycoprotein receptors have different number of $\mathrm{N}$-glycan sites. The number of $\mathrm{N}$ - glycans is defined by the protein sequence of each glycoprotein, and the types of $\mathrm{N}$-glycan structures are determined by the Golgi $\mathrm{N}$ - glycan- processing pathway and metabolite sup- ply to sugar-nucleotide pools161. Receptors that stimu- late cell proliferation, growth and oncogenesis (such as EGFR, IGF receptor (IGFR), fibroblast growth factor (FGFR) and platelet- derived growth factor (PDGFR)) have more $\mathrm{N}$ - glycan sites (8-16 Asn- $\mathrm{X}$ - Ser/Thr sites, in which $\mathrm{X}$ is any amino acid) per 100 amino acids, and longer extracellular domains. Conversely, growth-arrest receptors involved in organogenesis and differentiation (such as TGF $\beta$ receptor 1 (TGF $\beta R_{1}$ ) and TGF $\beta R_{2}$ ) have few $\mathrm{N}$-glycan sites161. Lau et al. proposed a mechanism for metabolic regulation of cellular

INSTITUTO DE INVESTIIGAÇÃO EINOVAÇÃO EM SAUDE UNIVERSIDADE DO PORTO

Rua Alfredo Allen, 208 4200-135 Porto Portugal +351 220408800 
transition between cell proliferation and arrest and/or differentiation that arises from the cooperation of complex $\mathrm{N}$ - glycan num- ber and the degree of branching structures161. Changes in metabolic flux through the HBP affect the stability and retention of receptors at the cell surface by modulating the interaction of branched $\mathrm{N}^{-}$glycans with galectin- 3 (REFS 162,163). The galectin- 3 lattice restricts receptor endocytosis, enhancing the signalling68,161. Hence, the more $\mathrm{N}$ - glycan sites, the more $\beta_{1}, 6$-branching structures are added, which crosslink with galectins, precluding endocytosis and thereby increasing signalling161,162. Mammary carcinoma cells derived from polyomavirus middle T (PyMT) Mgat5-l-- transgenic mice are less responsive to IGF, EGF, PDGF, FGF and TGF $\beta$ compared with Mgat5+/+ tumour cells, showing reduced galectin- 3 binding and internalization of receptors from the cell surface to endosomes164. Similarly, human cancer cells with targeted silencing of the MGAT5 gene also exhibit reduced EGFR signalling165. Sensitivity to EGF and TGF $\beta$ cytokines was rescued by hexosamine supplementation with UDP-GICNAc or by GnT-V expression, implying that remodelling of $\mathrm{N}$-glycans in tumour cells is sensitive to metabolism161. Accordingly, the decrease of galectin lattice interactions induced by the addition of bisecting GlcNAc N-glycans counterbalances the highly branched $\mathrm{N}$ - glycosylation of EGFR and PDGFR, restraining its downstream signalling and in this way retarding mam- mary tumour progression166. GnT- III overexpression reduces the ability of EGF to bind to its receptor, blocking EGFR- mediated ERK phosphorylation and increasing EGFR endocytosis167. Increasing intracellular metabolic flux with UDP-GIcNAc promotes a hyperbolic activation profile for high- $\mathrm{n}$ receptors (receptors with a high number of $\mathrm{N}$ - glycan sites (growth receptors)) and a sigmoid or switch- like profile for low- $\mathrm{n}$ receptors (receptors with a reduced number of $\mathrm{N}$ - glycan sites (arrest receptors)), thereby regulating the transition between cell growth and differentiation 161 . Overall, the nutrient flux that regulates complex $\mathrm{N}$ - glycan biosynthesis coordinates the cellular response of tumour cells determining growth, invasion and drug sensitivity10o. Interestingly, the presence of branching $\mathrm{N}$-glycans on VEGFR2 interacting with galectin-1 underlies an aberrant and compensatory angiogenesis mechanism associated with tumour growth in tumours resistant to anti-VEGF treatment69. Gangliosides have been described as important modulators of signal transduction. Ectopic expression or inhibition of specific glycosyltransferases modifying gangliosides regulates RTK signalling. Within glycolipid-enriched microdomains, RTKs can be modulated by glycans, resulting in inhibition of ligand - induced dimerization and autophosphorylation or in activation of receptor signalling without ligand binding. The RTK modulation depends on the glycan structure; monosialogangliosides (such as $\mathrm{GM}_{3}$ and $\mathrm{GM}_{1}$ ) are considered negative regulators of RTKs, whereas disialo- gangliosides (such as $\mathrm{GD}_{2}, \mathrm{GD}_{3}$, GD1a and $\mathrm{GD}_{1} \mathrm{~b}$ ) are considered activators of RTKs17. Furthermore, physio- pathological changes in cell membrane ganglioside com- position have been shown to result in different cellular responses168. Several growth factor receptors, including EGFR, FGFR, PDGF, MET and IGFR, are regulated by gangliosides17,53,169. RTKs are located in glycolipid- enriched microdomains, and changes in gangliosides modify the molecular composition and the structure of glycolipid-enriched microdomains, leading to modifi- cations in the location and organization of RTKs in the cellular membrane and altered activation53,169. Further regulation of specific ganglioside $\mathrm{GD}_{3}$ due to formation of $9^{-} \mathrm{O}$ - acetyl $\mathrm{GD}_{3}$ that renders GD3 unable to induce apoptosis has been shown in gliomas170.

\section{Glycans in tumour immune surveillance}

Glycans regulate various aspects of the immune response interfering with tumour editing. Such regulation is mediated by various lectins - such as galectins, C - type lectins and siglecs - that bind glycans and regulate immune processes such as those relevant for pathogen recognition, thereby 
defining the course of adaptive immune responses171,172. Cancer immune surveillance is an important host protection process thought to inhibit carcino- genesis and maintain cellular homeostasis. Transformed cells can be eliminated by immune effector cells, resulting in immune selection of tumour cell variants with decreased immunogenicity and resistance to immune effector cells. Glycan- specific natural and induced antibodies (such as those against GM2, globo $\mathrm{H}$ and Ley) can mediate tumour cell killing and tissue destruction by complement- dependent cytotoxicity173. In addition, aberrant $\mathrm{O}$-glycosylation on the surface of cancer cells can induce antibody- dependent cellular cytotoxicity $(A D C C) 174$ and may interact with dendritic cell- specific intercellular adhesion molecule- 3 grabbing non-integrin 1 (DC-SIGN; also known as CD209)175 and macrophage galactose- type $\mathrm{C}$ - type lectin176 expressed on denditric cells. Galectins can also modulate the immune and inflammatory responses and might have a key role helping tumours to escape immune surveillance, therefore having diagnostic and prognostic applications171,177-179. Targeting altered glycosylation as an immunothera- peutic strategy - for example, with anticancer vaccines that target tumour-associated carbohydrate antigens18o - provides an appealing option for cancer treatment92. Examples include vaccines targeting the mucin- related $\mathrm{Tn}, \mathrm{STn}$, and T antigens for suppression of breast cancer, the gangliosides $\mathrm{GM}_{2}$ and $\mathrm{GD}_{3}$ for treatment of mela- noma, and the glycosphingolipid globo- $\mathrm{H}$ for prostate cancer treatment 181 . Some of these anticancer vaccines can be designed to incorporate only those elements required for a desired immune response182-184. Antibodies targeting GD2 disialo- ganglioside have been tested in numerous clinical trials in neuroblastoma with impressive antitumour effects and survival outcomes185. Passive immunotherapy using antibodies directed to glycoform-specific targets expressed in tumour cells can be effective at inducing ADCC 174 . Other studies have shown that $A D C C$ is a key mechanism by which some currently used therapeutic antibodies mediate their antitumour effects. Variations of glycosylation on the heavy chain of the therapeutic antibodies can increase the affinity between the antibody and Fcy receptor, resulting in increased ADCC186.

\section{Glycans in cancer diagnosis and treatment}

New approaches for cancer early diagnosis, risk prediction and treatment are urgently needed, and glycans can be a source for the development of new non-invasive biomarkers. Some of the most-common clinically utilized sero- logical biomarkers for cancer diagnosis and monitoring of malignant progression, as well as prognostic biomarkers of disease recurrence, are glycoproteins3,49. These include prominent biomarkers that are widely used in patients with prostate cancer (prostate- specific anti- gen (PSA))187, ovarian cancer (carcinoma antigen 125 (CA125; also known as mucin-16 (MUC16)))188, colon cancer (SLea, CA19-9, 3,49 and carcinoembryonic antigen (CEA)189), breast cancer (aberrantly glycosylated MUC1 (also known as CA15-3))190,191 gastric cancer (SLea, CA19-9)3,49 and pancreatic cancer (SLea, CA19-9)192 (TABLE 1). Although all of these serological biomarkers have been shown to have an aberrant glyco sylation in cancer193-195, they have limited application owing to their relative low specificity, precluding their use for screening strategies and diagnostic potential. The reduced specificity and sensitivity of these assays for early detection of cancer has driven a search for novel biomarkers based on the detection and measurement of specific glyco- forms of a certain protein that could contribute to the establishment of a biomarker with higher specificity for early detection of cancer or for diagnosis at a precancerous stage. A story of success is that of $\alpha$-fetoprotein (AFP), a glyco-biomarker used for the detection of liver diseases. AFP is a broadly validated protein for diagnosis of $\mathrm{HCC}_{5}$; however, serum levels of AFP do not allow dis- crimination between HCC and the benign liver diseases. Therefore, an additional tumour marker was proposed, based on a

INSTITUTO DEINVESTİGAÇÃO E INOVACCÃO EM SAÚDE UNIVERSIDADE DO PORTO

Rua Alfredo Allen, 208 4200-135 Porto Portugal +351220408800 info@i3s.up.pt www.i3s.up.pt 
glycosylated form of AFP (the AFP- $\mathrm{L}_{3}$ frac- tion) that shows a highly significant increase in the fuco- sylation index in HCC patients in comparison to chronic liver diseases196. The fucosylated AFP - L3 fraction was approved by FDA as a marker for early detection of HCC that appears in serum at the stage of liver cirrhosis, just before the onset of HCC, being therefore considered the best approved marker in patients with $\mathrm{HCC}_{6}, 196$. Other liver-secreted proteins, such as GP73, kininogen and haptoglobin, have been shown to be fucosylated, acting as promising biomarkers for early detection of HCC and disease progression197. With the advent of new technologies and new methods for glycan analysis, many examples of aberrant glycans associated with cancer were discovered198. The recent application of precise and stable glycogene editing in mammalian cell lines combined with high-throughput mass spectrometry approaches has contributed to the characterization of the $\mathrm{O}$ - glycoproteome of cancer cells, disclosing new biological information and generating putative disease biomarkers199,200. In addition, the newly developed highthroughput platform technologies have further enabled the analysis of large cohorts of samples in an efficient manner198,201. An increased concentration of fucosylated haptoglobin occurs in serum of patients with pancreatic cancer compared with that of patients with other types of cancer, such as gastric cancer or CRC, and healthy controls202. Recently, STn antigen was found in circulating $\mathrm{CD}_{44}$ in serum from patients with gastric cancer200. In addition, STn has been found in plasminogen in serum from patients with intestinal metaplasia and gastric carcinomazo3. Additional studies showed altered glycosylation (both fucosylation and sialylation) in PSA as a specific biomarker for prostate cancer that is able to distinguish it from benign pros- tate hyperplasia187,204. Therefore, it is likely that targeting glycans in combination with the protein backbone will provide greater diagnostic and prognostic perfor- mance, with sufficient sensitivity and specificity for clinical applications. Additionally, circulating exosomes enriched in certain glycoconjugates have major potential for early detection of cancer. This is the case of proteoglycan glypican 1 (GPC1), which has been shown to identify circulating pancreatic cancer exosomes and allows the early detection of this cancer205. Serum antibodies against tumour-associated glycan antigens have been shown to have potential applications as biomarkers for early cancer detection206. The detection of aberrant glycosylated $M_{U} C_{1-}$ specific autoantibodies correlates with CRC, predicting this cancer with $95 \%$ specificity 207 . However, the low sensitivity of the assay supports the use of it in combination with other mark- ers, suggesting that a combination of antibody signa- tures may eventually enable a biomarker panel for the early detection of cancer207. Furthermore, microarrays of glyco peptides displaying cancer-associated glycans open new avenues for the expansion of glycoconjugates and glycoforms for further cancer biomarker discovery with potential clinical applications206. In summary, the impressive progress in the under- standing the role of glycans in cancer in the recent years has contributed to the discovery of glycans as promising biomarkers, highlighting their application in the clinical setting as appealing targets for personalized medicine180.

\section{Conclusions and perspectives}

Glycosylated proteins and other glycoconjugates are major components of cells, defining and modulating several key physiological processes in normal tissues. Genetic, epigenetic, metabolic, inflammatory and envi- ronmental mechanisms can lead to modifications of glycosylation that drive several biological processes in cancer. The understanding of the molecular basis under- lying these glycan modifications will further contribute to explain cancer cell interactions, extracellular com- munications (including extracellular vesicles and exo- some communication) and cancer immunology. The foreseeable new knowledge in the glycobiology field, with the rapid expansion of 
novel (glyco)engineered cell and model platforms, which are providing increas - ing advances in the understanding of how glycosylation modulates biological functions, will allow the develop- ment of a relatively unexploited field of drugs based on inhibitors, glycan antagonists and glycan-function mod- ulators. Furthermore, the combination of an increasing amount of data on glycomics and glycoproteomics and the recent advances in genomics, transcriptomics, prot- eomics and metabolomics will have a major impact on the unravelling of novel targets and strategies for the early diagnosis, prognosis, patient stratification and improved treatment of cancer. 


\section{REFERENCES}

1. Fuster, M. M. \& Esko, J. D. The sweet and sour of cancer: glycans as novel therapeutic targets. Nat. Rev. Cancer 5, 526-542 (2005).

2. Hakomori, S. Glycosylation defining cancer malignancy: new wine in an old bottle. Proc. Natl Acad. Sci. USA 99, 10231-10233 (2002).

3. Reis, C. A., Osorio, H., Silva, L., Gomes, C. \& David, L. Alterations in glycosylation as biomarkers for cancer detection. J. Clin. Pathol. 63, 322-329 (2010).

4. Taniguchi, N., Hancock, W., Lubman, D. M. \& Rudd, P. M. The second golden age of glycomics: from functional glycomics to clinical applications. J. Proteome Res. 8, 425-426 (2009).

5. Pinho, S. S. et al. Gastric cancer: adding glycosylation to the equation. Trends Mol. Med. 19, 664676 (2013).

6. Freeze, H. H. Understanding human glycosylation disorders: biochemistry leads the charge. J. Biol. Chem. 288, 6936-6945 (2013). This Review describes the genetic and biochemical advances in the diagnosis of several inherited human glycosylation disorders.

7. Ohtsubo, K. \& Marth, J. D. Glycosylation in cellular mechanisms of health and disease. Cell 126, $855-867$ (2006).

8. Varki, A. et al. (eds) Essentials of Glycobiology 2nd edn (Cold Spring Harbor Laboratory Press, 2009).

9. Cummings, R. D. The repertoire of glycan determinants in the human glycome. Mol. Biosyst. 5 , 1087-1104 (2009).

10. Gabius, H. J., Andre, S., Jimenez-Barbero, J., Romero, A. \& Solis, D. From lectin structure to functional glycomics: principles of the sugar code. Trends Biochem. Sci. 36, 298-313 (2011).

11. Moremen, K.W., Tiemeyer, M. \& Nairn, A.V. Vertebrate protein glycosylation: diversity, synthesis and function. Nat. Rev. Mol. Cell Biol. 13, 448-462 (2012).

12. Bennett, E. P. et al. Control of mucin-type O-glycosylation: a classification of the polypeptide GalNAc-transferase gene family. Glycobiology 22, 736-756 (2012). This article reports on the biological function of the polypeptide GalNAc transferase gene family, the largest glycosyltransferase enzyme family.

13. Clausen, H. \& Bennett, E.P. A family of UDP-GalNAc: polypeptide N-acetylgalactosaminyltransferases control the initiation of mucin-type O-linked glycosylation. Glycobiology 6, 635-646 (1996).

14. Brockhausen, I., Yang, J., Lehotay, M., Ogata, S. \& Itzkowitz, S. Pathways of mucin Oglycosylation in normal and malignant rat colonic epithelial cells reveal a mechanism for cancerassociated sialyl-Tn antigen expression. Biol. Chem. 382, 219-232 (2001). This Review describes the pathways of mucin-type O-glycosylation.

15. Ma, J. \& Hart, G. W. O-GlcNAc profiling: from proteins to proteomes. Clin. Proteomics 11, 8 (2014).

INSTITUTO DE INVESTİGAÇÃO E INOVACCÃO EM SAÚDE UNIVERSIDADE DO PORTO

Rua Alfredo Allen, 208 4200-135 Porto Portugal +351220408800 
16. Luther, K. B. \& Haltiwanger, R. S. Role of unusual O-glycans in intercellular signaling. Int. J. Biochem. Cell Biol. 41, 1011-1024 (2009).

17. Julien, S., Bobowski, M., Steenackers, A., Le Bourhis, X. \& Delannoy, P. How do gangliosides regulate RTKs signaling? Cells 2, 751-767 (2013).

18. Ladenson, R. P., Schwartz, S. O. \& Ivy, A. C. Incidence of the blood groups and the secretor factor in patients with pernicious anemia and stomach carcinoma. Am. J. Med. Sci. 217, 194-197 (1949).

19. Hakomori, S.I. \& Murakami, W. T. Glycolipids of hamster fibroblasts and derived malignanttransformed cell lines. Proc. Natl Acad. Sci. USA 59, 254-261 (1968).

20. Feizi, T. Carbohydrate antigens in human cancer. Cancer Surv. 4, 245-269 (1985).

21. Holmes, E. H., Ostrander, G. K., Clausen, H. \& Graem, N. Oncofetal expression of Lex carbohydrate antigens in human colonic adenocarcinomas. Regulation through type 2 core chain synthesis rather than fucosylation. J. Biol. Chem. 262, 11331-11338 (1987).

22. Hakomori, S. \& Kannagi, R. Glycosphingolipids as tumor-associated and differentiation markers. J. Natl Cancer Inst. 71, 231-251 (1983).

23. Marcos, N. T. et al. ST6GalNAc-I controls expression of sialyl-Tn antigen in gastrointestinal tissues. Front. Biosci. (Elite Ed.) 3, 1443-1455 (2011).

24. Julien, S. et al. ST6GaINAc I expression in MDA-MB-231 breast cancer cells greatly modifies their O-glycosylation pattern and enhances their tumourigenicity. Glycobiology 16, 54-64 (2006).

25. Kannagi, R., Yin, J., Miyazaki, K. \& Izawa, M. Current relevance of incomplete synthesis and neosynthesis for cancer-associated alteration of carbohydrate determinants-Hakomori's concepts revisited. Biochim. Biophys. Acta 1780, 525-531 (2008). This Review describes the incomplete synthesis and neo-synthesis processes as two major concepts for cancer-associated alterations of cell-surface carbohydrate determinants.

26. Buckhaults, P., Chen, L., Fregien, N. \& Pierce, M. Transcriptional regulation of Nacetylglucosaminyltransferase V by the src oncogene. J. Biol. Chem. 272, 19575-19581 (1997).

27. Hatano, K., Miyamoto, Y., Nonomura, N. \& Kaneda, Y. Expression of gangliosides, GD1a, and sialyl paragloboside is regulated by NF-KBdependent transcriptional control of $\alpha 2,3-$ sialyltransferase I, II, and VI in human castration-resistant prostate cancer cells. Int. J. Cancer 129, 1838-1847 (2011).

28. Pinho, S. S. et al. Loss and recovery of Mgat3 and GnT-III Mediated E-cadherin N-glycosylation is a mechanism involved in epithelial-mesenchymalepithelial transitions. PLoS ONE 7, e33191 (2012).

29. Schietinger, A. et al. A mutant chaperone converts a wild-type protein into a tumor-specific antigen. Science 314, 304-308 (2006).

30. Aryal, R.P., Ju, T. \& Cummings, R. D. The endoplasmic reticulum chaperone Cosmc directly promotes in vitro folding of T -synthase. J. Biol. Chem. 285, 2456-2462 (2010). 
31. Kakugawa, Y. et al. Up-regulation of plasma membraneassociated ganglioside sialidase (Neuz) in human colon cancer and its involvement in apoptosis suppression. Proc. Natl Acad. Sci. USA 99, 10718-10723 (2002).

32. Kumamoto, K. et al. Increased expression of UDPgalactose transporter messenger RNA in human colon cancer tissues and its implication in synthesis of Thomsen-Friedenreich antigen and sialyl Lewis A/X determinants. Cancer Res. 61, 4620-4627 (2001).

33. Kellokumpu, S., Sormunen, R. \& Kellokumpu, I. Abnormal glycosylation and altered Golgi structure in colorectal cancer: dependence on intra-Golgi pH. FEBS Lett. 516, 217-224 (2002).

34. Gill, D. J., Chia, J., Senewiratne, J. \& Bard, F. Regulation of O-glycosylation through Golgi-to-ER relocation of initiation enzymes. J. Cell Biol. 189, 843-858 (2010).

35. Brockhausen, I. Mucin-type O-glycans in human colon and breast cancer: glycodynamics and functions. EMBO Rep. 7, 599-604 (2006).

36. Marcos, N. T. et al. Role of the human ST6GaINAC-I and ST6GalNAC-II in the synthesis of the cancerassociated sialyl-Tn antigen. Cancer Res. 64, 7050-7057 (2004). This study demonstrates that ST6GalNAc-I is responsible for the biosynthesis of the STn antigen in gastric cancer cells.

37. Roth, J., Wang, Y., Eckhardt, A. E. \& Hill, R. L. Subcellular localization of the UDP-N-acetyldgalactosamine: polypeptide $\mathrm{N}$-acetylgalactosaminylt ransferase-mediated O-glycosylation reaction in the submaxillary gland. Proc. Natl Acad. Sci. USA 91, 8935-8939 (1994).

38. Sewell, R. et al. The ST6GaINAc-I sialyltransferase localizes throughout the Golgi and is responsible for the synthesis of the tumor-associated sialyl-Tn O-glycan in human breast cancer. J. Biol. Chem. 281, 3586-3594 (2006).

39. Christiansen, M. N. et al. Cell surface protein glycosylation in cancer. Proteomics $14,525-546$ (2014).

40. Arnold, J. N., Saldova, R., Hamid, U. M. \& Rudd, P. M. Evaluation of the serum N-linked glycome for the diagnosis of cancer and chronic inflammation. Proteomics 8, 3284-3293 (2008).

41. Kim, Y. J. \& Varki, A. Perspectives on the significance of altered glycosylation of glycoproteins in cancer. Glycoconj. J. 14, 569-576 (1997). 42. Dall'Olio, F. \& Chiricolo, M. Sialyltransferases in cancer. Glycoconj. J. 18, 841-850 (2001).

43. Lise, M. et al. Clinical correlations of $\alpha 2,6$-sialyltransferase expression in colorectal cancer patients. Hybridoma 19, 281-286 (2000).

44. Amado, M., Carneiro, F., Seixas, M., Clausen, H. \& Sobrinho-Simoes, M. Dimeric sialyl-Lex expression in gastric carcinoma correlates with venous invasion and poor outcome. Gastroenterology 114, 462-470 (1998).

45. Baldus, S. E. et al. Histopathological subtypes and prognosis of gastric cancer are correlated with the expression of mucin-associated sialylated antigens: Sialosyl-Lewisa, Sialosyl-Lewisx and sialosyl-Tn. Tumour Biol. 19, 445-453 (1998).

46. Rosen, S. D. \& Bertozzi, C. R. The selectins and their ligands. Curr. Opin. Cell Biol. 6, 663-673 (1994). 
47. Nakamori, S. et al. Increased expression of sialyl Lewisx antigen correlates with poor survival in patients with colorectal carcinoma: clinicopathological and immunohistochemical study. Cancer Res. 53, 3632-3637 (1993).

48. Borsig, L. et al. Heparin and cancer revisited: mechanistic connections involving platelets, Pselectin, carcinoma mucins, and tumor metastasis. Proc. Natl Acad. Sci. USA 98, 3352-3357 (2001).

49. Locker, G. Y. et al. ASCO 2006 update of recommendations for the use of tumor markers in gastrointestinal cancer. J. Clin. Oncol. 24, 5313-5327 (2006).

50. Marrelli, D. et al. Preoperative positivity of serum tumor markers is a strong predictor of hematogenous recurrence of gastric cancer. J. Surg. Oncol. 78, 253-258 (2001).

51. Tanaka, F. et al. Prognostic significance of polysialic acid expression in resected non-small cell lung cancer. Cancer Res. 61, 1666-1670 (2001).

52. Falconer, R. A., Errington, R. J., Shnyder, S. D., Smith, P. J. \& Patterson, L. H. Polysialyltransferase: a new target in metastatic cancer. Curr. Cancer Drug Targets 12, 925-939 (2012).

53. Todeschini, A. R., Dos Santos, J. N., Handa, K. \& Hakomori, S. I. Ganglioside GM2-tetraspanin CD82 complex inhibits met and its cross-talk with integrins, providing a basis for control of cell motility through glycosynapse. J. Biol. Chem. 282, 8123-8133 (2007).

54. Carvalho, A. S. et al. Differential expression of $\alpha-2,3-$ sialyltransferases and $\alpha-1,3 / 4^{-}$ fucosyltransferases regulates the levels of sialyl Lewis a and sialyl Lewis $\mathrm{x}$ in gastrointestinal carcinoma cells. Int. J. Biochem. Cell Biol. 42, 80-89 (2010).

55. de Vries, T., Knegtel, R. M., Holmes, E. H. \& Macher, B. A. Fucosyltransferases: structure/function studies. Glycobiology 11, 119R-128R (2001).

56. Hiraiwa, N. et al. Transactivation of the fucosyltransferase VII gene by human T -cell leukemia virus type 1 Tax through a variant cAMP-responsive element. Blood 101, 3615-3621 (2003).

57. Matsuura, N. et al. Gene expression of fucosyl- and sialyl-transferases which synthesize sialyl Lewisx, the carbohydrate ligands for E-selectin, in human breast cancer. Int. J. Oncol. 12, 1157-1164 (1998).

58. Holmes, E. H., Hakomori, S. \& Ostrander, G. K. Synthesis of type 1 and 2 lacto series glycolipid antigens in human colonic adenocarcinoma and derived cell lines is due to activation of a normally unexpressed $\beta 1 \rightarrow 3 \mathrm{~N}$-acetylglucosaminyltransferase. J. Biol. Chem. 262, 15649-15658 (1987).

59. Marcos, N. T. et al. Helicobacter pylori induces $\beta_{3} G_{n} T_{5}$ in human gastric cell lines, modulating expression of the SabA ligand sialyl-Lewis x. J. Clin. Invest. 118, 2325-2336 (2008).

6o. Magalhaes, A. et al. Helicobacter pylori chronic infection and mucosal inflammation switches the human gastric glycosylation pathways. Biochim. Biophys. Acta 1852, 1928-1939 (2015).

61. Trinchera, M. et al. The biosynthesis of the selectinligand sialyl Lewis $\mathrm{x}$ in colorectal cancer tissues is regulated by fucosyltransferase VI and can be inhibited by an RNA interference-based approach. Int. J. Biochem. Cell Biol. 43, 130-139 (2011). 
62. Liu, Y. C. et al. Sialylation and fucosylation of epidermal growth factor receptor suppress its dimerization and activation in lung cancer cells. Proc. Natl Acad. Sci. USA 108, 11332-11337 (2011).

63. Potapenko, I. O. et al. Glycan gene expression signatures in normal and malignant breast tissue; possible role in diagnosis and progression. Mol. Oncol. 4, 98-118 (2010).

64. Hutchinson, W. L., Du, M. Q., Johnson, P. J. \& Williams, R. Fucosyltransferases: differential plasma and tissue alterations in hepatocellular carcinoma and cirrhosis. Hepatology 13, 683-688 (1991).

65. Sato, Y. et al. Early recognition of hepatocellular carcinoma based on altered profiles of alphafetoprotein. N. Engl. J. Med. 328, 1802-1806 (1993). This study revealed the capacity of $\alpha-$ fetoprotein $\mathrm{L}_{3}$ and $\alpha$-fetoprotein $\mathrm{P}_{4}+\mathrm{P}_{5}$ in serum to act as predictive markers to differentiate $\mathrm{HCC}$ from cirrhosis.

66. Takahashi, M., Kuroki, Y., Ohtsubo, K. \& Taniguchi, N. Core fucose and bisecting GlcNAc, the direct modifiers of the $\mathrm{N}$-glycan core: their functions and target proteins. Carbohydr. Res. 344, 1387-1390 (2009).

67. Dennis, J. W., Laferte, S., Waghorne, C., Breitman, M. L. \& Kerbel, R. S. Beta 1-6 branching of Asn-linked oligosaccharides is directly associated with metastasis. Science 236, 582-585 (1987). This study reported that increased expression of $\beta_{1}-6$-linked branching oligosaccharide structures is directly related to the metastatic potential of the cells.

68. Di Lella, S. et al. When galectins recognize glycans: from biochemistry to physiology and back again. Biochemistry 50, 7842-7857 (2011).

69. Croci, D. O. et al. Glycosylation-dependent lectinreceptor interactions preserve angiogenesis in antiVEGF refractory tumors. Cell 156, 744-758 (2014). This article describes a glycosylationdependent pathway that preserves angiogenesis in anti-VEGF refractory tumours.

70. Demetriou, M., Nabi, I. R., Coppolino, M., Dedhar, S. \& Dennis, J. W. Reduced contact-inhibition and substratum adhesion in epithelial cells expressing GlcNAc-transferase V. J. Cell Biol. 130, 383392 (1995).

71. Seberger, P.J. \& Chaney, W. G. Control of metastasis by Asn-linked, $\beta_{1}-6$ branched oligosaccharides in mouse mammary cancer cells. Glycobiology 9, 235-241 (1999).

72. Guo, H. B. et al. Specific posttranslational modification regulates early events in mammary carcinoma formation. Proc. Natl Acad. Sci. USA 107, 21116-21121 (2010).

73. Granovsky, M. et al. Suppression of tumor growth and metastasis in Mgat5-deficient mice. Nat. Med. 6, 306-312 (2000). This study reports the establishment of mice deficient in Mgat 5 by targeted gene mutation. Mammary tumour growth and metastases induced by the polyomavirus middle $T$ oncogene were considerably suppressed in Mgat5-/- mice compared with in transgenic littermates expressing Mgat5.

74. Guo, H., Nagy, T. \& Pierce, M. Post-translational glycoprotein modifications regulate colon cancer stem cells and colon adenoma progression in Apcmin/+ mice through altered Wnt receptor signaling. J. Biol. Chem. 289, 31534-31549 (2014).

75. Yoshimura, M., Nishikawa, A., Ihara, Y., Taniguchi, S. \& Taniguchi, N. Suppression of lung metastasis of $\mathrm{B}_{1} 6$ mouse melanoma by $\mathrm{N}$-acetylglucosaminyltransferase III gene transfection. Proc. 
Natl Acad. Sci. USA 92, 8754-8758 (1995). This article provides the first demonstration of the tumour-suppressive role of GnT-III.

76. Zhao, Y. et al. Branched N-glycans regulate the biological functions of integrins and cadherins. FEBS J. 275, 1939-1948 (2008).

77. Kudelka, M. R., Ju, T., Heimburg-Molinaro, J. \& Cummings, R. D. Simple sugars to complex disease-mucin-type O-glycans in cancer. Adv. Cancer Res. 126, 53-135 (2015).

78. Berois, N. et al. GALNT9 gene expression is a prognostic marker in neuroblastoma patients. Clin. Chem. 59, 225-233 (2013).

79. Gomes, J. et al. Expression of UDP-N-acetyld-galactosamine: polypeptide Nacetylgalactosaminyltransferase- 6 in gastric mucosa, intestinal metaplasia, and gastric carcinoma. J. Histochem. Cytochem. 57, 79-86 (2009).

8o. Gill, D. J. et al. Initiation of GalNAc-type O-glycosylation in the endoplasmic reticulum promotes cancer cell invasiveness. Proc. Natl Acad. Sci. USA 110, E3152-E3161 (2013).

81. Dalziel, $\mathrm{M}$. et al. The relative activities of the $\mathrm{C}_{2} \mathrm{GnT}_{1}$ and $\mathrm{ST}_{3} \mathrm{Gal}_{-} \mathrm{I}$ glycosyltransferases determine O-glycan structure and expression of a tumor-associated epitope on MUC1. J. Biol. Chem. 276, 11007-11015 (2001).

82. Reis, C. A., David, L., Seixas, M., Burchell, J. \& Sobrinho-Simoes, M. Expression of fully and underglycosylated forms of MUC1 mucin in gastric carcinoma. Int. J. Cancer 79, 402-410 (1998).

83. Itzkowitz, S. etal. Expression of $\mathrm{Tn}$, sialosyl $\mathrm{Tn}$, and $\mathrm{T}$ antigens in human pancreas. Gastroenterology 100, 1691-1700 (1991).

84. Radhakrishnan, P. et al. Immature truncated O-glycophenotype of cancer directly induces oncogenic features. Proc. Natl Acad. Sci. USA 111, E4066-E4075 (2014).

85. Pinho, S. et al. Biological significance of cancerassociated sialyl-Tn antigen: modulation of malignant phenotype in gastric carcinoma cells. Cancer Lett. 249, 157-170 (2007).

86. David, L., Nesland, J. M., Clausen, H., Carneiro, F. \& Sobrinho-Simoes, M. Simple mucin-type carbohydrate antigens ( $T n$, sialosyl-Tn and $T$ ) in gastric mucosa, carcinomas and metastases. APMIS Suppl. 27, 162-172 (1992).

87. Dall'Olio, F., Malagolini, N., Trinchera, M. \& Chiricolo, M. Mechanisms of cancer-associated glycosylation changes. Front. Biosci. (Landmark Ed.) 17, 670-699 (2012).

88. Ferreira, J. A. et al. Overexpression of tumourassociated carbohydrate antigen sialyl-Tn in advanced bladder tumours. Mol. Oncol. 7, 719-731 (2013).

89. Ricardo, S. et al. Detection of glyco-mucin profiles improves specificity of MUC 16 and MUC 1 biomarkers in ovarian serous tumours. Mol. Oncol. 9, 503-512 (2015).

90. Ju, T. \& Cummings, R. D. A unique molecular chaperone Cosmc required for activity of the mammalian core 1 ß3-galactosyltransferase. Proc. Natl Acad. Sci. USA 99, 16613-16618 (2002). This study describes the role of the molecular chaperone $C_{1} G_{A L T} C_{1}$ for activity of the core $1 \beta_{3}-G$ alT. 
91. Ju, T. et al. Human tumor antigens Th and sialyl Tn arise from mutations in Cosmc. Cancer Res. $68,1636-1646$ (2008).

92. Julien, S. et al. Sialyl-Tn vaccine induces antibodymediated tumour protection in a relevant murine model. Br. J. Cancer 100, 1746-1754 (2009).

93. Sandmaier, B. M. et al. Evidence of a cellular immune response against sialyl-Tn in breast and ovarian cancer patients after high-dose chemotherapy, stem cell rescue, and immunization with Theratope STn-KLH cancer vaccine. J. Immunother. 22, 54-66 (1999).

94. Pinho, S. S. et al. E-cadherin and adherens-junctions stability in gastric carcinoma: functional implications of glycosyltransferases involving N-glycan branching biosynthesis, $\mathrm{N}$ acetylglucosaminyltransferases III and V. Biochim. Biophys. Acta 1830, 2690-2700 (2013). This article reports the biological significance of GnT-III and GnT-V in the modulation of Ecadherinmediated cell-cell adhesion in cancer.

95. Pinho, S. S. et al. The role of $\mathrm{N}$-acetylglucosaminyltransferase III and $\mathrm{V}$ in the posttranscriptional modifications of E-cadherin. Hum. Mol. Genet. 18, 2599-2608 (2009).

96. Takeuchi, H. \& Haltiwanger, R. S. Significance of glycosylation in Notch signaling. Biochem. Biophys. Res. Commun. 453, 235-242 (2014).

97. Boscher, C., Dennis, J. W. \& Nabi, I. R. Glycosylation, galectins and cellular signaling. Curr. Opin. Cell Biol. 23, 383-392 (2011).

98. de-Freitas-Junior, J. C. et al. Insulin/IGF-I signaling pathways enhances tumor cell invasion through bisecting GlcNAc N-glycans modulation. an interplay with E-cadherin. PLoS ONE 8, e81579 (2013).

99. Gomes, C. et al. Expression of $\mathrm{ST}_{3} \mathrm{GAL}_{4}$ leads to SLex expression and induces c-Met activation and an invasive phenotype in gastric carcinoma cells. PLoS ONE 8, e66737 (2013).

100. Dennis, J. W., Nabi, I. R. \& Demetriou, M. Metabolism, cell surface organization, and disease. Cell 139, 1229-1241 (2009).

101. Bassaganas, S. et al. Pancreatic cancer cell glycosylation regulates cell adhesion and invasion through the modulation of $\alpha_{2} \beta_{1}$ integrin and E-cadherin function. PLoS ONE 9, eg8595 (2014).

102. Helenius, A. \& Aebi, M. Intracellular functions of N-linked glycans. Science $291,2364-2369$ (2001).

103. Pinho, S. S. et al. Modulation of E-cadherin function and dysfunction by N-glycosylation. Cell. Mol. Life Sci. 68, 1011-1020 (2011).

104. Paredes, J. et al. Epithelial E- and P-cadherins: role and clinical significance in cancer. Biochim. Biophys. Acta 1826, 297-311 (2012).

105. Liwosz, A., Lei, T. \& Kukuruzinska, M. A. N-glycosylation affects the molecular organization and stability of E-cadherin junctions. J. Biol. Chem. 281, 23138-23149 (2006).

106. Guo, H. B., Lee, I., Kamar, M. \& Pierce, M. N-acetylglucosaminyltransferase V expression levels regulate cadherin-associated homotypic cell-cell adhesion and intracellular signaling pathways. J. Biol. Chem. 278, 52412-52424 (2003). 
107. Ihara, S. et al. Prometastatic effect of $\mathrm{N}$-acetylglucosaminyltransferase $\mathrm{V}$ is due to modification and stabilization of active matriptase by adding $\beta_{1}-6$ GlcNAc branching. J. Biol. Chem. 277, 1696o16967 (2002).

108. Carvalho, S. et al. Preventing E-cadherin aberrant N-glycosylation at Asn-554 improves its critical function in gastric cancer. Oncogene http://dx.doi. org/10.1038/onc.2015.225 (2015).

109. Yoshimura, M., Ihara, Y., Matsuzawa, Y. \& Taniguchi, N. Aberrant glycosylation of E-cadherin enhances cell-cell binding to suppress metastasis. J. Biol. Chem. 271, 13811-13815 (1996).

110. Kitada, $\mathrm{T}$. et al. The addition of bisecting $\mathrm{N}$-acetylglucosamine residues to $\mathrm{E}$-cadherin downregulates the tyrosine phosphorylation of betacatenin. J. Biol. Chem. 276, 475-480 (2001).

111. $\mathrm{Xu}, \mathrm{Q}$. et al. Roles of $\mathrm{N}$-acetylglucosaminyltransferase III in epithelial-to-mesenchymal transition induced by transforming growth factor $\beta_{1}$ (TGF- $\left.\beta_{1}\right)$ in epithelial cell lines. J. Biol. Chem. $287,16563-16574$ (2012).

112. Gu, J. et al. A mutual regulation between cell-cell adhesion and $\mathrm{N}$-glycosylation: implication of the bisecting GlcNAc for biological functions. J. Proteome Res. 8, 431-435 (2009).

113. Dennis, J.W., Granovsky, M. \& Warren, C.E. Glycoprotein glycosylation and cancer progression. Biochim. Biophys. Acta 1473, 21-34 (1999).

114. Pinho, S. S., Reis, C. A., Gartner, F. \& Alpaugh, M. L. Molecular plasticity of E-cadherin and sialyl lewis $x$ expression, in two comparative models of mammary tumorigenesis. PLoS ONE 4, e6636 (2009).

115. Seidenfaden, R., Krauter, A., Schertzinger, F., Gerardy-Schahn, R. \& Hildebrandt, H. Polysialic acid directs tumor cell growth by controlling heterophilic neural cell adhesion molecule interactions. Mol. Cell. Biol. 23, 5908-5918 (2003). This study demonstrates the role of polysialic acid on neural cell adhesion molecule in cancer cells.

116. Lin, S., Kemmner, W., Grigull, S. \& Schlag, P. M. Cell surface $\alpha 2,6$ sialylation affects adhesion of breast carcinoma cells. Exp. Cell Res. 276, 101-110 (2002).

117. Tamura, F. et al. RNAi-mediated gene silencing of ST6GalNAc I suppresses the metastatic potential in gastric cancer cells. Gastric Cancer http://dx.doi. org/10.1007/s10120-014-0454-z (2014).

118. Kim, S. H., Turnbull, J. \& Guimond, S. Extracellular matrix and cell signalling: the dynamic cooperation of integrin, proteoglycan and growth factor receptor. J. Endocrinol. 209, 139-151 (2011).

119. Sarrazin, S., Lamanna, W. C. \& Esko, J. D. Heparan sulfate proteoglycans. Cold Spring Harb. Perspect. Biol. 3, aoo4952 (2011).

120. Wade, A. et al. Proteoglycans and their roles in brain cancer. FEBS J. 280, 2399-2417 (2013).

121. Cecchi, F. et al. Targeted disruption of heparan sulfate interaction with hepatocyte and vascular endothelial growth factors blocks normal and oncogenic signaling. Cancer Cell 22, 250-262 (2012).

122. Tan, K. W. et al. Neutrophils contribute to inflammatory lymphangiogenesis by increasing VEGF-A bioavailability and secreting VEGF-D. Blood 122, 3666-3677 (2013). 123. Gunthert, U. et al. 
A new variant of glycoprotein $\mathrm{CD}_{44}$ confers metastatic potential to rat carcinoma cells. Cell $65,13-$ 24 (1991).

124. da Cunha, C. B. et al. De novo expression of $\mathrm{CD}_{44}$ variants in sporadic and hereditary gastric cancer. Lab. Invest. 90, 1604-1614 (2010).

125. English, N. M., Lesley, J. F. \& Hyman, R. Site-specific de-N-glycosylation of CD44 can activate hyaluronan binding, and $\mathrm{CD}_{44}$ activation states show distinct threshold densities for hyaluronan binding. Cancer Res. 58, 3736-3742 (1998).

126. Katoh, S., Zheng, Z., Oritani, K., Shimozato, T. \& Kincade, P. W. Glycosylation of CD44 negatively regulates its recognition of hyaluronan. J. Exp. Med. 182, 419-429 (1995).

127. Goupille, C., Hallouin, F., Meflah, K. \& Le Pendu, J. Increase of rat colon carcinoma cells tumorigenicity by $\alpha(1-2)$ fucosyltransferase gene transfection. Glycobiology 7, 221-229 (1997).

128. Wolff, E. A. etal. Generation of artificial proteoglycans containing glycosaminoglycanmodified CD44. Demonstration of the interaction between rantes and chondroitin sulfate. J. Biol. Chem. 274, 2518-2524 (1999).

129. Roucourt, B., Meeussen, S., Bao, J., Zimmermann, P. \& David, G. Heparanase activates the syndecansyntenin-ALIX exosome pathway. Cell Res. 25, 412-428 (2015).

130. Bharadwaj, A. G. et al. Spontaneous metastasis of prostate cancer is promoted by excess hyaluronan synthesis and processing. Am. J. Pathol. 174, 1027-1036 (2009).

131. Paszek, M. J. et al. The cancer glycocalyx mechanically primes integrin-mediated growth and survival. Nature 511, 319-325(2014).

132. Liotta, L. A. Tumor invasion and metastases-role of the extracellular matrix: Rhoads Memorial Award lecture. Cancer Res. 46, 1-7 (1986).

133. Jin, H. \& Varner, J. Integrins: roles in cancer development and as treatment targets. $\mathrm{Br}$. J. Cancer 90, 561-565(2004).

134. Asada, M., Furukawa, K., Segawa, K., Endo, T. \& Kobata, A. Increased expression of highly branched $\mathrm{N}$-glycans at cell surface is correlated with the malignant phenotypes of mouse tumor cells. Cancer Res. 57, 1073-1080 (1997).

135. Guo, H. B., Lee, I., Kamar, M., Akiyama, S. K. \& Pierce, M. Aberrant N-glycosylation of $\beta_{1}$ integrin causes reduced $\alpha_{5} \beta_{1}$ integrin clustering and stimulates cell migration. Cancer Res. 62 , 6837-6845 (2002).

136. Pochec, E. et al. Expression of integrins $\alpha_{3} \beta_{1}$ and $\alpha_{5} \beta_{1}$ and GlcNAc $\beta_{1}, 6$ glycan branching influences metastatic melanoma cell migration on fibronectin. Eur. J. Cell Biol. 92, 355-362 (2013).

137. Isaji, T. et al. Introduction of bisecting GlcNAc into integrin $\alpha_{5} \beta_{1}$ reduces ligand binding and downregulates cell adhesion and cell migration. J. Biol. Chem. 279, 19747-19754 (2004).

138. Zhao, Y. et al. N-acetylglucosaminyltransferase III antagonizes the effect of $\mathrm{N}$ acetylglucosaminyltransferase $\mathrm{V}$ on $\alpha_{3} \beta_{1}$ integrinmediated cell migration. J. Biol. Chem. 281, 32122-32130 (2006). 
139. Gu, J. \& Taniguchi, N. Regulation of integrin functions by N-glycans. Glycoconj. J. 21, 9-15 (2004).

140. Dennis, J., Waller, C., Timpl, R. \& Schirrmacher, V. Surface sialic acid reduces attachment of metastatic tumour cells to collagen type IV and fibronectin. Nature 300, 274-276 (1982).

141. Seales, E. C. et al. Hypersialylation of $\beta_{1}$ integrins, observed in colon adenocarcinoma, may contribute to cancer progression by up-regulating cell motility. Cancer Res. 65, 4645-4652 (2005).

142. Kariya, Y., Kawamura, C., Tabei, T. \& Gu, J. Bisecting GlcNAc residues on laminin-332 downregulate galectin-3-dependent keratinocyte motility. J. Biol. Chem. 285, 3330-3340 (2010).

143. Ranjan, A., Bane, S. M. \& Kalraiya, R. D. Glycosylation of the laminin receptor $\left(\alpha_{3} \beta_{1}\right)$ regulates its association with tetraspanin $\mathrm{CD}_{151}$ : impact on cell spreading, motility, degradation and invasion of basement membrane by tumor cells. Exp. Cell Res. 322, 249-264 (2014).

144. Vlodavsky, I. \& Friedmann, Y. Molecular properties and involvement of heparanase in cancer metastasis and angiogenesis. J. Clin. Invest. 108, 341-347 (2001).

145. Lendorf, M. E., Manon-Jensen, T., Kronqvist, P., Multhaupt, H. A. \& Couchman, J. R. Syndecan1 and syndecan-4 are independent indicators in breast carcinoma. J. Histochem. Cytochem. 59, $615-629$ (2011).

146. Saoncella, S. et al. Syndecan-4 signals cooperatively with integrins in a Rho-dependent manner in the assembly of focal adhesions and actin stress fibers. Proc. Natl Acad. Sci. USA 96, 2805-2810 (1999). This article describes how a proteoglycan cooperates with integrins interfering with focal adhesions and actin stress fibres.

147. Beauvais, D. M., Burbach, B. J. \& Rapraeger, A. C. The syndecan-1 ectodomain regulates $\alpha v \beta_{3}$ integrin activity in human mammary carcinoma cells. J. Cell Biol. 167, 171-181 (2004).

148. Warburg, O. On the origin of cancer cells. Science 123, 309-314 (1956).

149. Marshall, S., Bacote, V. \& Traxinger, R. R. Discovery of a metabolic pathway mediating glucose-induced desensitization of the glucose transport system. Role of hexosamine biosynthesis in the induction of insulin resistance. J. Biol. Chem. 266, 4706-4712 (1991).

150. Wells, L., Vosseller, K. \& Hart, G. W. Glycosylation of nucleocytoplasmic proteins: signal transduction and O-GlcNAc. Science 291, 2376-2378 (2001).

151. Slawson, C., Copeland, R. J. \& Hart, G. W. O-GlcNAc signaling: a metabolic link between diabetes and cancer? Trends Biochem. Sci. 35, 547-555 (2010).

152. Ferrer, C. M. et al. O-GlcNAcylation regulates cancer metabolism and survival stress signaling via regulation of the HIF-1 pathway. Mol. Cell 54, 820-831 (2014).

153. Ma, Z. \& Vosseller, K. Cancer metabolism and elevated O-GlcNAc in oncogenic signaling. J. Biol. Chem. 289, 34457-34465 (2014).

154. Caldwell, S. A. et al. Nutrient sensor O-GlcNAc transferase regulates breast cancer tumorigenesis through targeting of the oncogenic transcription factor FoxM1. Oncogene 29, 28312842 (2010). 
155. Zachara, N. E. \& Hart, G. W. Cell signaling, the essential role of O-GlcNAc! Biochim. Biophys. Acta 1761, 599-617 (2006).

156. Lynch, T. P. et al. Critical role of O-linked $\beta$-N-acetylglucosamine transferase in prostate cancer invasion, angiogenesis, and metastasis. J. Biol. Chem. 287, 11070-11081 (2012).

157. Zhu, W., Leber, B. \& Andrews, D. W. Cytoplasmic O-glycosylation prevents cell surface transport of E-cadherin during apoptosis. EMBO J. 20, 5999-6007 (2001).

158. Hart, G. W., Slawson, C., Ramirez-Correa, G. \& Lagerlof, O. Cross talk between OGlcNAcylation and phosphorylation: roles in signaling, transcription, and chronic disease. Annu. Rev. Biochem. 80, 825-858 (2011).

159. Itkonen, H. M. et al. O-GlcNAc transferase integrates metabolic pathways to regulate the stability of c-MYC in human prostate cancer cells. Cancer Res. 73, 5277-5287 (2013).

16o. Yang, W. H. et al. Modification of $\mathrm{p} 53$ with $\mathrm{O}$-linked $\mathrm{N}$-acetylglucosamine regulates $\mathrm{p} 53$ activity and stability. Nat. Cell Biol. 8, 1074-1083 (2006).

161. Lau, K. S. et al. Complex N-glycan number and degree of branching cooperate to regulate cell proliferation and differentiation. Cell 129, 123-134 (2007). 162. Stanley, P. A method to the madness of N-glycan complexity? Cell 129, 27-29 (2007).

163. Taniguchi, N. A sugar-coated switch for cellular growth and arrest. Nat. Chem. Biol. 3, 307-309 (2007).

164. Partridge, E. A. et al. Regulation of cytokine receptors by Golgi N-glycan processing and endocytosis. Science 306, 120-124 (2004).

165. Guo, H. B., Johnson, H., Randolph, M., Lee, I. \& Pierce, M. Knockdown of GnT -Va expression inhibits ligand-induced downregulation of the epidermal growth factor receptor and intracellular signaling by inhibiting receptor endocytosis. Glycobiology 19, 547-559 (2009).

166. Song, Y., Aglipay, J. A., Bernstein, J. D., Goswami, S. \& Stanley, P. The bisecting GlcNAc on Nglycans inhibits growth factor signaling and retards mammary tumor progression. Cancer Res. 70, 3361-3371 (2010).

167. Sato, $\mathrm{Y}$. et al. Overexpression of $\mathrm{N}$-acetylglucosaminyltransferase III enhances the epidermal growth factor-induced phosphorylation of ERK in $\mathrm{HeLaS}_{3}$ cells by up-regulation of the internalization rate of the receptors. J. Biol. Chem. 276, 11956-11962 (2001).

168. Bremer, E. G. \& Hakomori, S. Gangliosides as receptor modulators. Adv. Exp. Med. Biol. 174, 381-394 (1984). 169. Park, S. Y., Yoon, S. J., Freire-de-Lima, L., Kim, J. H. \& Hakomori, S. I. Control of cell motility by interaction of gangliosides, tetraspanins, and epidermal growth factor receptor in A 431 versus KB epidermoid tumor cells. Carbohydr. Res. 344, 1479-1486 (2009).

170. Birks, S. M. et al. Targeting the $\mathrm{GD}_{3}$ acetylation pathway selectively induces apoptosis in glioblastoma. Neuro Oncol. 13, 950-960 (2011).

171. Rabinovich, G. A. \& Toscano, M. A. Turning 'sweet' on immunity: galectin-glycan interactions in immune tolerance and inflammation. Nat. Rev. Immunol. 9, 338-352 (2009). 
172. Macauley, M. S., Crocker, P. R. \& Paulson, J.C. Siglecmediated regulation of immune cell function in disease. Nat. Rev. Immunol. 14, 653-666 (2014).

173. Ragupathi, G. et al. Antibodies against tumor cell glycolipids and proteins, but not mucins, mediate complement-dependent cytotoxicity. J. Immunol.

174, 5706-5712 (2005). 174. Lavrsen, K. et al. Aberrantly glycosylated MUC1 is expressed on the surface of breast cancer cells and a target for antibody-dependent cell-mediated cytotoxicity. Glycoconj. J. 30, 227-236 (2013).

175. Samsen, A. et al. DC-SIGN and SRCL bind glycans of carcinoembryonic antigen (CEA) and CEArelated cell adhesion molecule 1 (CEACAM1): recombinant human glycan-binding receptors as analytical tools. Eur. J. Cell Biol. 89, 87-94 (2010).

176. Saeland, E. et al. The C-type lectin MGL expressed by dendritic cells detects glycan changes on $\mathrm{MUC}_{1}$ in colon carcinoma. Cancer Immunol. Immunother. 56, 1225-1236 (2007).

177. Laubli, H. et al. Lectin galactoside-binding soluble 3 binding protein (LGALS3BP) is a tumorassociated immunomodulatory ligand for CD33-related Siglecs. J. Biol. Chem. 289, 33481-33491 (2014).

178. Liu, F. T. \& Rabinovich, G. A. Galectins as modulators of tumour progression. Nat. Rev. Cancer 5, 29-41 (2005).

179. Thijssen, V. L., Heusschen, R., Caers, J. \& Griffioen, A. W. Galectin expression in cancer diagnosis and prognosis: a systematic review. Biochim. Biophys. Acta 1855, 235-247 (2015).

18o. Dalziel, M., Crispin, M., Scanlan, C. N., Zitzmann, N. \& Dwek, R. A. Emerging principles for the therapeutic exploitation of glycosylation. Science 343, 1235681 (2014). Addresses the potential of glycans to be an important source for the development of novel targeted therapeutic strategies.

181. Slovin, S. F. et al. Carbohydrate vaccines in cancer: immunogenicity of a fully synthetic globo $\mathrm{H}$ hexasaccharide conjugate in man. Proc. Natl Acad. Sci. USA 96, 5710-5715 (1999).

182. Buskas, T., Thompson, P. \& Boons, G. J. Immunotherapy for cancer: synthetic carbohydratebased vaccines. Chem Commun. 2009, 5335-5349 (2009).

183. Li, M., Song, L. \& Qin, X. Glycan changes: cancer metastasis and anti-cancer vaccines. J. Biosci. $35,665-673$ (2010).

184. Beatson, R. E., Taylor-Papadimitriou, J. \& Burchell, J. M. MUC1 immunotherapy. Immunotherapy 2, 305-327 (2010).

185. Mackall, C. L., Merchant, M. S. \& Fry, T. J. Immunebased therapies for childhood cancer. Nat. Rev. Clin. Oncol. 11, 693-703 (2014).

186. Liu, S. D. et al. Afucosylated antibodies increase activation of FcyRllla-dependent signaling components to intensify processes promoting ADCC. Cancer Immunol. Res. 3, 173-183 (2015).

187. Gilgunn, S., Conroy, P. J., Saldova, R., Rudd, P. M. \& O'Kennedy, R. J. Aberrant PSA glycosylation - a sweet predictor of prostate cancer. Nat. Rev. Urol. 10, 99-107 (2013). Describes the potential of altered PSA-glycosylation patterns to be used as a reliable diagnostic tool in discriminating between significant and insignificant prostate cancers. 
188. Zurawski, V. R. Jr, Orjaseter, H., Andersen, A. \& Jellum, E. Elevated serum CA 125 levels prior to diagnosis of ovarian neoplasia: relevance for early detection of ovarian cancer. Int. J. Cancer 42, $677-680$ (1988).

189. Goldstein, M. J. \& Mitchell, E. P. Carcinoembryonic antigen in the staging and follow-up of patients with colorectal cancer. Cancer Invest. 23, 338-351 (2005).

190. Ebeling, F. G. et al. Serum CEA and CA $15^{-13}$ as prognostic factors in primary breast cancer. Br. J. Cancer 86, 1217-1222 (2002).

191. Kumpulainen, E. J., Keskikuru, R. J. \& Johansson, R. T. Serum tumor marker CA 15.3 and stage are the two most powerful predictors of survival in primary breast cancer. Breast Cancer Res. Treat. 76, 95-102 (2002).

192. Safi, F., Schlosser, W., Kolb, G. \& Beger, H. G. Diagnostic value of CA 19-19 in patients with pancreatic cancer and nonspecific gastrointestinal symptoms. J. Gastrointest. Surg. 1, 106-112 (1997).

193. Fukushima, K., Satoh, T., Baba, S. \& Yamashita, K. $\alpha 1,2$-fucosylated and $\beta$-Nacetylgalactosaminylated prostate-specific antigen as an efficient marker of prostatic cancer. Glycobiology 20, 452-460 (2010).

194. Jankovic, M. M. \& Milutinovic, B. S. Glycoforms of CA125 antigen as a possible cancer marker. Cancer Biomark. 4, 35-42 (2008).

195. Saeland, E. et al. Differential glycosylation of MUC 1 and $C_{E A C A M} 5$ between normal mucosa and tumour tissue of colon cancer patients. Int. J. Cancer 131, 117-128 (2012).

196. Noda, K. et al. Gene expression of $\alpha_{1}-6$ fucosyltransferase in human hepatoma tissues: a possible implication for increased fucosylation of $\alpha$-fetoprotein. Hepatology 28, 944-952 (1998).

197. Wang, M. et al. Novel fucosylated biomarkers for the early detection of hepatocellular carcinoma. Cancer Epidemiol. Biomarkers Prev. 18, 1914-1921 (2009).

198. Adamczyk, B., Tharmalingam, T. \& Rudd, P. M. Glycans as cancer biomarkers. Biochim. Biophys. Acta 1820, 1347-1353 (2012).

199. Steentoft, C. et al. Mining the O-glycoproteome using zinc-finger nuclease-glycoengineered SimpleCell lines. Nat. Methods 8, 977-982 (2011). Describes the development of the SimpleCell strategy using zinc-finger nucleases for the characterization of the O-glycoproteome of cancer cells.

200. Campos, D. et al. Probing the O-glycoproteome of gastric cancer cell lines for biomarker discovery. Mol. Cell. Proteomics 14, 1616-1629 (2015). Details the characterization of the Oglycoproteome of gastric cancer cells and serum from patients with gastric cancer.

201. Lauc, G. et al. Genomics meets glycomics - the first GWAS study of human N-glycome identifies HNF $1 \alpha$ as a master regulator of plasma protein fucosylation. PLoS Genet. 6, e1001256 (2010).

202. Miyoshi, E. \& Nakano, M. Fucosylated haptoglobin is a novel marker for pancreatic cancer: detailed analyses of oligosaccharide structures. Proteomics 8, 3257-3262 (2008). 
203. Gomes, C. et al. Glycoproteomic analysis of serum from patients with gastric precancerous lesions. J. Proteome Res. 12, 1454-1466 (2013).

204. Saldova, R., Fan, Y., Fitzpatrick, J. M., Watson, R. W. \& Rudd, P. M. Core fucosylation and $\alpha 2-3$ sialylation in serum $\mathrm{N}$-glycome is significantly increased in prostate cancer comparing to benign prostate hyperplasia. Glycobiology 21, 195-205 (2011).

205. Melo, S. A. et al. Glypican-1 identifies cancer exosomes and detects early pancreatic cancer. Nature 523, 177-182 (2015).

206. Blixt, O. et al. Autoantibodies to aberrantly glycosylated $M \mathrm{MC}_{1}$ in early stage breast cancer are associated with a better prognosis. Breast Cancer Res. 13, R25 (2011).

207. Pedersen, J.W. et al. Cancer-associated autoantibodies to $\mathrm{MUC}_{1}$ and $\mathrm{MUC}_{4}-$ a blinded casecontrol study of colorectal cancer in UK collaborative trial of ovarian cancer screening. Int. J. Cancer 134, 2180-2188 (2014).

208. Moloney, D. J. et al. Mammalian Notch1 is modified with two unusual forms of O-linked glycosylation found on epidermal growth factor-like modules. J. Biol. Chem. 275, 9604-9611 (2000).

209. Panin, V. M., Papayannopoulos, V., Wilson, R. \& Irvine, K. D. Fringe modulates Notch-ligand interactions. Nature 387, 908-912 (1997).

210. Cohen, B. et al. Fringe boundaries coincide with Notch-dependent patterning centres in mammals and alter Notch-dependent development in Drosophila. Nat. Genet. 16, 283-288 (1997).

211. Tanaka, H. et al. Acute myelogenous leukemia with PIG-A gene mutation evolved from aplastic anemiaparoxysmal nocturnal hemoglobinuria syndrome. Int. J. Hematol. 73, 206-212 (2001).

212. Ilver, D. et al. Helicobacter pylori adhesin binding fucosylated histo-blood group antigens revealed by retagging. Science 279, 373-377 (1998).

213. Mahdavi, J. et al. Helicobacter pylori SabA adhesin in persistent infection and chronic inflammation. Science 297, 573-578 (2002).

214. Magalhaes, A., Ismail, M. N. \& Reis, C. A. Sweet receptors mediate the adhesion of the gastric pathogen Helicobacter pylori: glycoproteomic strategies. Expert Rev. Proteomics 7, 307-310 (2010).

215. Sarrats, A. et al. Glycosylation of liver acute-phase proteins in pancreatic cancer and chronic pancreatitis. Proteomics Clin. Appl. 4, 432-448 (2010).

216. Dias, A. M. et al. Dysregulation of T cell receptor N-glycosylation: a molecular mechanism involved in ulcerative colitis. Hum. Mol. Genet. 23, 2416-2427 (2014).

217. Samraj, A. N. et al. A red meat-derived glycan promotes inflammation and cancer progression. Proc. Natl Acad. Sci. USA 112, 542-547 (2015).

218. Chou, H. H. et al. A mutation in human CMP-sialic acid hydroxylase occurred after the HomoPan divergence. Proc. Natl Acad. Sci. USA 95, 11751-11756 (1998).

219. Ychou, M., Duffour, J., Kramar, A., Gourgou, S. \& Grenier, J. Clinical significance and prognostic value of $\mathrm{CA}_{72-4}$ compared with CEA and CA19-9 in patients with gastric cancer. Dis. Markers 16, 105-110 (2000). 
220. Valmu, L., Alfthan, H., Hotakainen, K., Birken, S. \& Stenman, U. H. Site-specific glycan analysis of human chorionic gonadotropin $\beta$-subunit from malignancies and pregnancy by liquid chromatography - electrospray mass spectrometry. Glycobiology 16, 1207-1218 (2006).

\section{ACKNOWLEDGEMENTS}

The Institute of Molecular Pathology and Immunology of the University of Porto integrates the Institute for Research and Innovation in Health, which is partially supported by the Portuguese Foundation for Science and Technology (FCT). This work is funded by the European Regional Development Fund (FEDER) through the Operational Programme for Competitiveness Factors (COMPETE) and by national funds through the FCT, under the projects PEst-C/SAU/ LAo003/2013, PTDC/BBB-EBI/0786/2012 and EXPL/BIMMEC/0149/2012. S.S.P. acknowledges a grant from the FCT (number SFRH/BPD/63094/2009). C.A.R. acknowledges support from the European Union Seventh Framework Programme GastricGlycoExplorer (grant number 316929). The authors apologize that they cannot include all the relevant studies on glycosylation in cancer in this article owing to limitation of space. The authors thank Tiago FontesOliveira for support in figures preparations.

Competing interests statement. The authors declare no competing interests. 

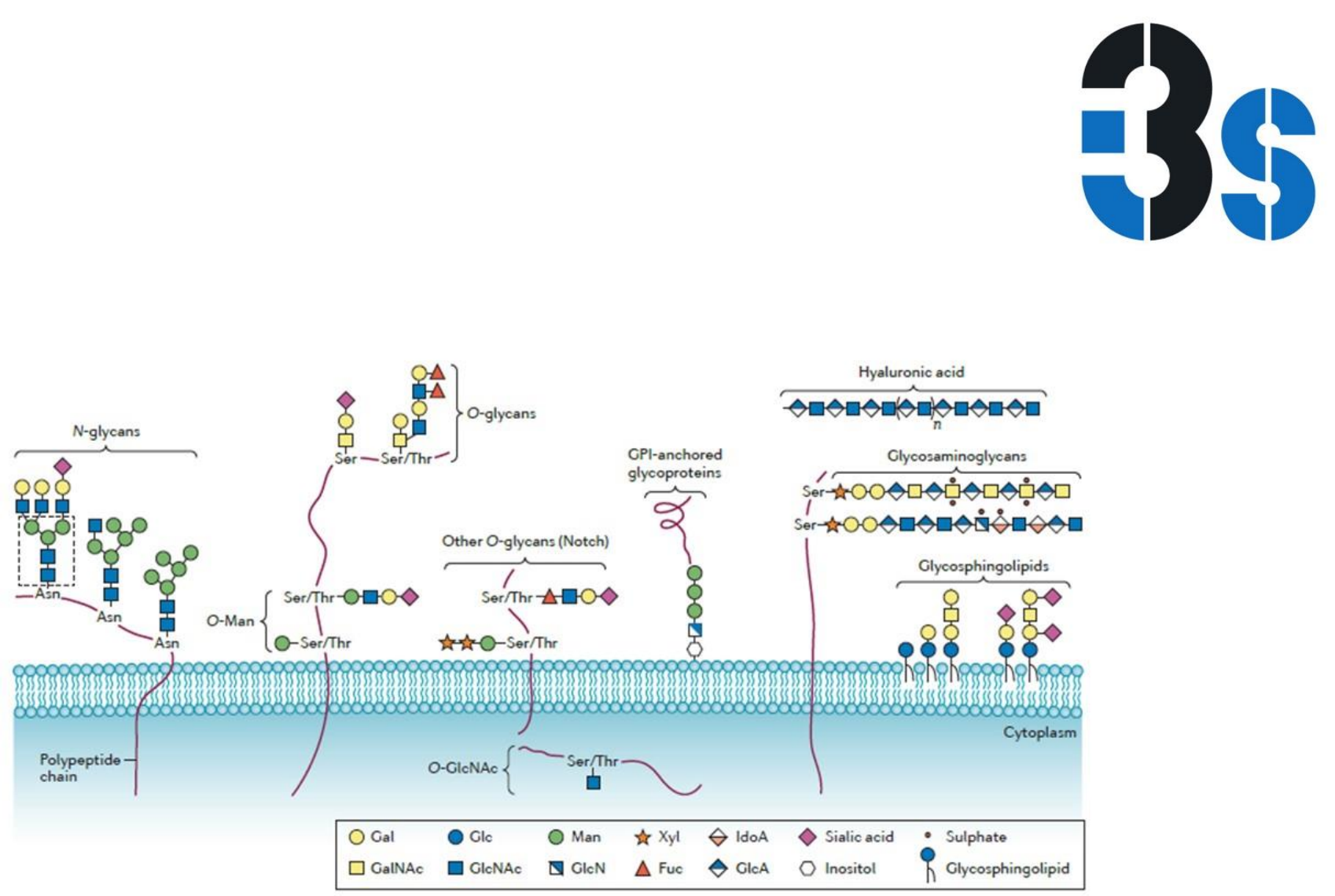

Figure 1 | Common classes of glycoconjugates in mammalian cells. Glycans can be found in various types of macromolecules. Glycosphingolipids are major components of the outer leaflet of the cell plasma membrane. These ceramide-linked glycans are made of a variable series of structures that can be further modified with terminal sialic acids8,17. Proteins can be glycosylated by the covalently attachment of a saccharide to a polypeptide backbone, via $N$ - linkage to Asp or $O$-linkage to Ser/Thr8. Mucin-type O-glycans are frequently found in secreted or membraneassociated glycoproteins and are initiated by $N$-acetylgalactosamine (GalNAc) $O$-linked to Ser/Thr13. O-glycans can be extended, producing various 'cores' and different terminal structures that are usually fucosylated and sialylated14. Other types of $O$-glycans include the $O$-mannose (O-Man), O-fucose (O-Fuc), $O$-galactose (O-Gal) and nucleocytoplasmic $O$-linked $\beta$ - $N$-acetylglucosamine $(O-G \mid c N A c) 11,15 . N$-glycosylation occurs in the consensus peptide sequences Asn-X-Ser/Thr (in which $X$ denotes any amino acid). $\mathrm{N}$-glycans share a common pentasaccharide core region (highlighted in the figure as a dotted line box) that can be further diversified into oligomannose, hybrid or complex types and further modified by the terminal structures GIcNAc, Gal and sialic acid8. Some glycoproteins can also be found in the outer leaflet of the plasma membrane linked to a phosphatidylinositol; these are called glycosylphosphatidylinositol (GPI)-anchored proteins8. Glycosaminoglycans are linear co-polymers of acidic disaccharide repeating units mostly found attached to the so-called proteoglycans8. An exception is hyaluronic acid, which is a glycosaminoglycan found free in the extracellular matrix. 


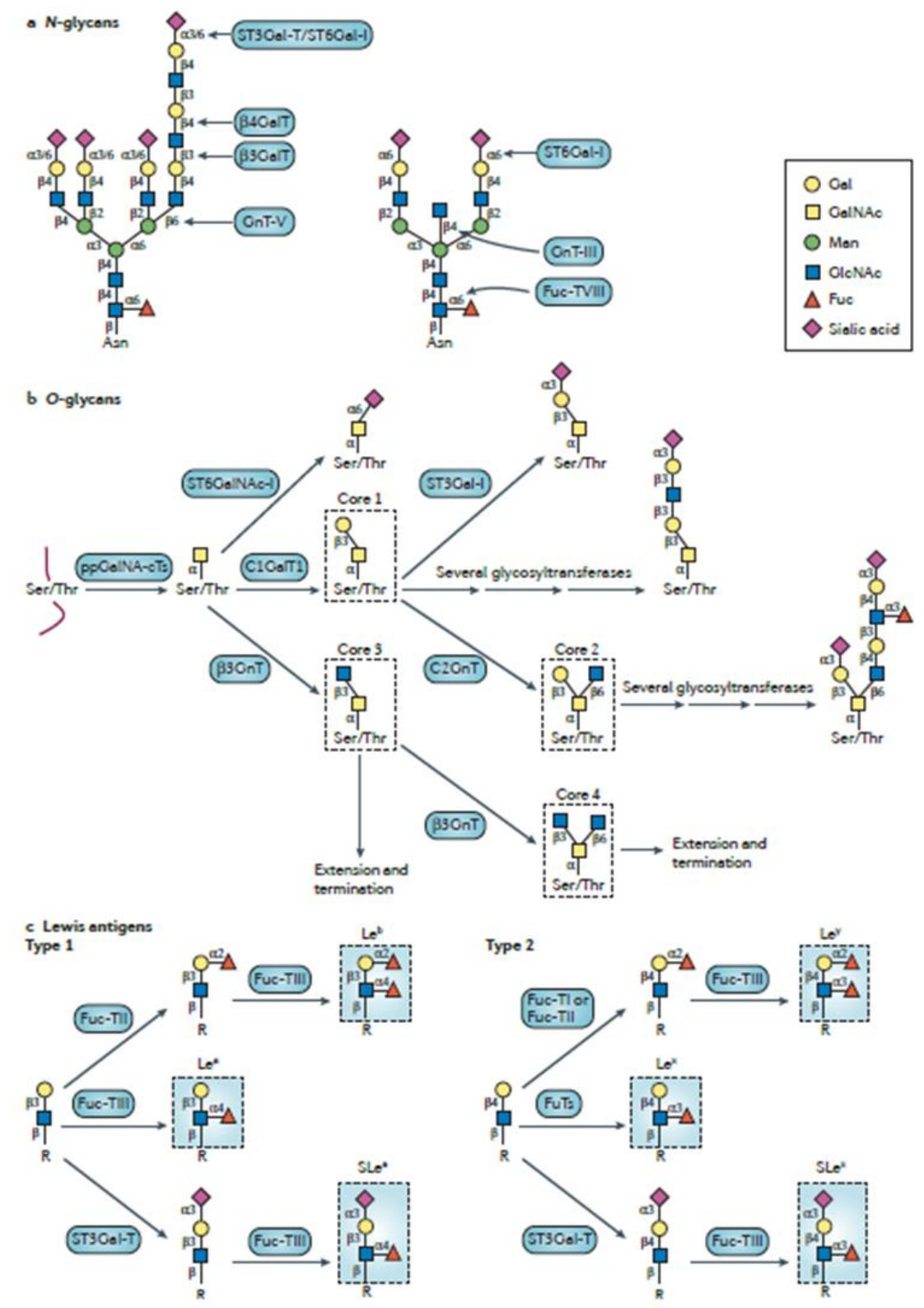

Figure 2 | Schematic representation of important glycan structures. The figure represents specific $\mathrm{N}$-linked (a) and $\mathrm{O}$-linked (b) glycan structures, as well as the terminal Lewis and sialylated Lewis structures (c). The key enzymes responsible for the addition of specific sugar residues are also shown in blue boxes. Examples include the polypeptide $N$-acetylgalactosamine transferases (ppGalNAc-Ts; a family of 20 enzymes, including GalNAc-T1, GalNAc-T2, GalNAc-T3, GalNAc-T4, GaINAc-T5 and GalNAc-T6), sialyltransferases (such as $\alpha$-galactoside $\alpha-2,6$-sialyltransferase I (ST6Gal-I), $\alpha 2,3$-sialyltransferases (ST3Gal-Ts) and $\alpha$-GalNAc ST6Gal-I (ST6GalNAc-I)), $N$-acetylglucosamine (GlcNAc) transferases (GnTs; such as GnT-III, GnT-V, core 2 GnTs (C2GnTs) 
and $\beta_{3} G n T$ ) and fucosyltransferases (Fuc-Ts). The latter include Fuc-TVIII (which mediates the addition of 'core' $\alpha_{1}, 6$ Fuc to $N$-glycans); Fuc-TI and Fuc-TIl, which add fucose (Fuc) in $\alpha_{1,2}$ linkage to galactose (Gal); Fuc-Ts that mediate the addition of Fuc in $\alpha 1,3$ linkage to an $\alpha 2,3$-sialylated type 2 chain (Fuc-TIII, Fuc-TIV, Fuc-TV, Fuc-TVI, Fuc-TVII and Fuc-TIX); and Fuc-Ts that add Fuc in $\alpha 1,4$ linkage to an $\alpha 2,3$-sialylated type 1 chain (Fuc-TIII and Fuc-TV). The blue boxes highlighted in part $c$ show the carbohydrate terminal Lewis antigens. Lewis type 1 antigens includes Lewis a (Lea), Leb and sialyl Lewis a (SLea); the type 2 group includes Lex, Ley and SLex. C1GalT1, core 1 GalNAc $\beta 1,3-G a l T$ 1; GalT, galactosyltransferase; GlcA, glucuronic acid; Man, mannose; STn, sialyl Tn. 

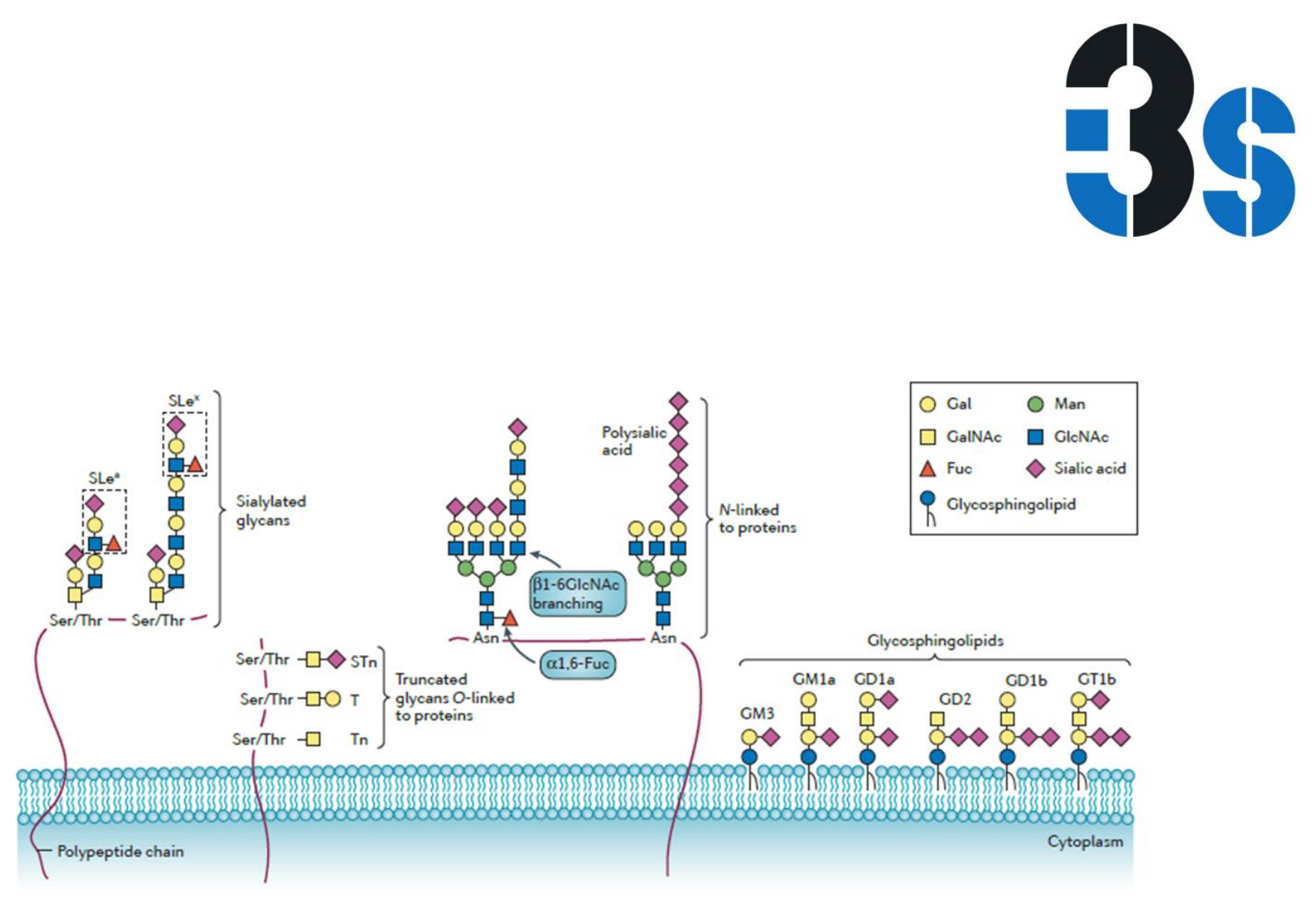

Figure 3 | Important tumour-associated glycans. Tumour cells often display glycans with different structures and levels of expression compared with their normal counterparts. These tumour-specific glycans are considered a hallmark of cancer cells. The most-widely occurring changes in glycosylation associated with cancer include an increase in overall sialylation2,25. Aberrant glycosylation in cancer frequently involves an increase in sialyl Lewis $x$ (SLex) and SLea (REF. 41) antigens, as well as an increase in terminal $\alpha 2,6$-sialylated structures, both in truncated $O$-linked glycans (such as sialyl Tn (STn))23,35,38 and in $N$-linked glycans113, and an increase in the $\alpha 2,8$-linked polymer known as polysialic acid52. Moreover, certain sialic acid-containing glycosphingolipids called gangliosides (including monosialogangliosides, such as $\mathrm{GM}_{3}$ and $\mathrm{GM}_{1}$, disialogangliosides, such as GD1a, GD2 and GD1b, and trisialogangliosides, such as GT1b) have been associated with malignancy 17. Another broadly occurring change in glycosylation associated with cancer is an enhancement of $\beta_{1}, 6-N$-acetylglucosamine ( $\left.\beta_{1}, 6 \mathrm{GlcNAc}\right)$-branched structures in $N$-linked glycans caused by an increased activity of $N$-acetylglucosaminyltransferase $V(G n T-V) 67$. Overexpression of 'core' fucosylation (the addition of $\alpha 1,6$-fucose ( $\alpha 1,6$-Fuc) to the innermost GlcNAc of $N$-glycans) by fucosyltransferase VIII (Fuc-TVIII) is also considered an important event in tumour development and progression196.Gal, galactose; GalNAc, N-acetylgalactosamine; Man, mannose. 


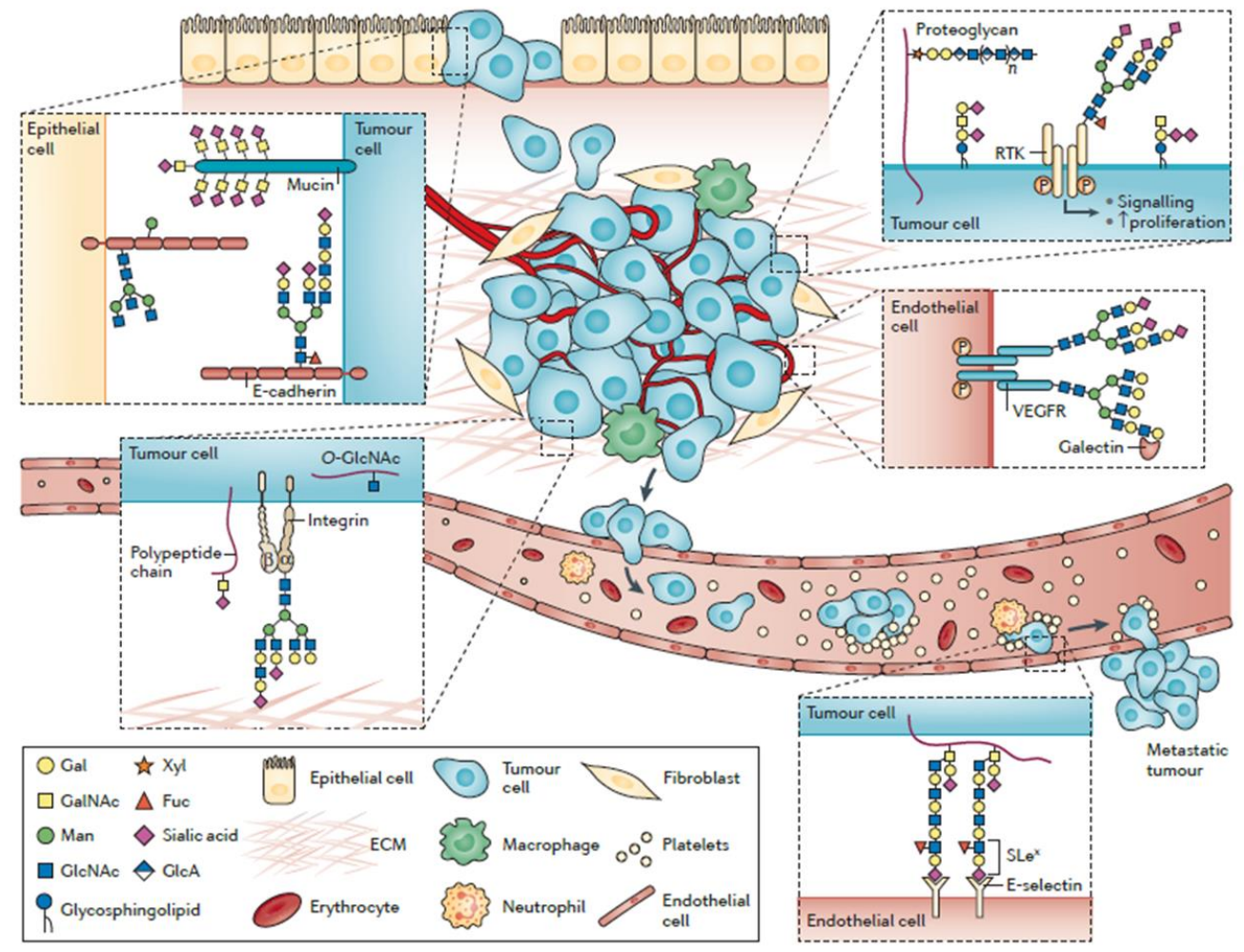

Figure 4 | Role of glycans in cancer development and progression. Glycans play fundamental parts in key pathological steps of tumour development and progression. In the process of tumour cell dissociation and invasion, glycans interfere with cell-cell adhesion. The modification of epithelial cadherin (E-cadherin) with $\beta_{1}, 6-N$-acetylglucosamine ( $\beta_{1}, 6 \mathrm{GlcNAc}$ )-branched $N$-glycan structures through enhanced $N$-acetylglucosaminyltransferase $V(G n T-V)$ activity impairs cell adhesion and promotes tumour cell invasiong4. These branched structures can be extended and the $\alpha 2,6$-sialylated terminal structures interfere with tumour cell adhesion. The presence of E-cadherin $N$-glycans with bisecting GlcNAc structures catalysed by GnT-III leads to protein stability and suppression of tumour progression75,94,95. Aberrant $O$-glycosylation, such as expression of sialyl Tn (STn) owing to overexpression of $\alpha$ - $N$-acetylgalactosamine ( $\alpha$-GaINAc) $\alpha-2,6$-sialyltransferase I

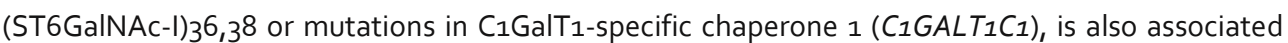
with tumour cell invasion 84,85 . The process of tumour growth and proliferation is characterized by altered glycosylation of key growth factors receptors, which modulates their activity and signalling161. Expression of gangliosides in the cancer cell membrane can also modulate signal transduction, activating various cellular pathways that induce tumour growth and progressioni7. Altered O-GlcNAcylation is also associated with cancer progression153. In the process of tumour cell migration, integrins show altered glycosylation in both $\mathrm{O}$-linked and $\mathrm{N}$-linked glycans76. Terminal sialylation interferes with cell-extracellular matrix (ECM) interactions, promoting an increased migratory and invasive phenotype140. The aberrant glycosylation of vascular endothelial growth factor receptor (VEGFR) modulates its interaction with galectins and is associated with 
tumour angiogenesis69. The tumour-associated carbohydrate determinants sialyl Lewis $x$ (SLex) and SLea serve as ligands for the adhesion receptors expressed in activated endothelial cells (E-selectin), platelets (P-selectin) and leukocytes (L-selectin), promoting cancer cell adhesion and metastasis46. Fuc, fucose; Gal, galactose; GlcA, glucuronic acid; Man, mannose; RTK, receptor tyrosine kinase; $\mathrm{Xyl}$, xylose. 


\begin{tabular}{|llllr|}
\hline $\begin{array}{l}\text { Serological } \\
\text { marker }\end{array}$ & $\begin{array}{l}\text { Glycoprotein or } \\
\text { glycoform }\end{array}$ & Cancers & Application in the clinic & Refs \\
\hline AFP & $\begin{array}{l}\text { AFP'core' fucosylation } \\
\text { (AFP-L3) }\end{array}$ & $\begin{array}{l}\text { Hepatocellular } \\
\text { carcinoma }\end{array}$ & Early diagnosis and monitoring & 65.196 \\
\hline CA19-9 & SLe & $\begin{array}{l}\text { Biliary, colorectal, } \\
\text { gastric and pancreatic }\end{array}$ & $\begin{array}{l}\text { Therapeutic monitoring. } \\
\text { recurrence and tumour burden }\end{array}$ & 49.192 \\
\hline CA72-4 & STn & Gastric & Monitoring & 219 \\
\hline CA15-3 & MUC1 & Breast & Monitoring & 190.191 \\
\hline CA125 & MUC16 & Ovarian & Monitoring and recurrence & 188 \\
\hline CEA & CEA & Colorectal & Monitoring and recurrence & 189 \\
\hline PSA & PSA & Prostate & Diagnosis, monitoring and & 187 \\
\hline$\beta-h C G$ & r-hCG & Gynaecological & Monitoring & 220 \\
\hline$\beta-h C G, \beta-h u m a n$
\end{tabular}

$\beta$-hCC. $\beta$-human chorionic gonadotropin; AFP, a-fetoprotein; CA, cancer antigen; CEA, carcinoembryonic antigen; MUC. mucin: PSA, prostate specific antigen; SLe*, sialyl Lewis a: STn, sialyl Tn.

Table 1 | Examples of serological markers with clinical applications 